\title{
Evaluation of oxygen species during E-H transition in inductively coupled RF plasmas: combination of experimental results with global model
}

\author{
Jürgen Meichsner and Thomas Wegner ${ }^{\mathrm{a}}$ \\ Institute of Physics, University of Greifswald, Felix-Hausdorff-Str. 6, 17489 Greifswald, Germany
}

Received: 24.11.2017 / Revised version: 22.12.2017

\begin{abstract}
Inductively coupled RF plasmas (ICP) in oxygen at low pressure have been intensively studied as a molecular and electronegative model system in the last funding period of the Collaborative Research Center 24 "Fundamentals of Complex Plasmas". The ICP configuration consists of a planar coil inside a quartz cylinder as dielectric barrier which is immersed in a large stainless steel vacuum chamber. In particular, the E-H mode transition has been investigated, combining experimental results from comprehensive plasma diagnostics as input for analytical rate equation calculation of a volume averaged global model. The averaged density was determined for electrons, negative ions $\mathrm{O}^{-}$, molecular oxygen ground state $\mathrm{O}_{2}\left(\mathrm{X}^{3} \Sigma_{\mathrm{g}}^{-}\right)$and singlet metastable state $\mathrm{O}_{2}\left(\mathrm{a}^{1} \Delta_{\mathrm{g}}\right)$ from line-integrated measurements using $160 \mathrm{GHz}$ Gaussian beam microwave interferometry coupled with laser photodetachment experiment and VUV absorption spectroscopy, respectively. Taking into account the relevant elementary processes and rate coefficients from literature together with the measured temperatures and averaged density of electrons, $\mathrm{O}_{2}\left(\mathrm{X}^{3} \Sigma_{\mathrm{g}}^{-}\right)$ and $\mathrm{O}_{2}\left(\mathrm{a}^{1} \Delta_{\mathrm{g}}\right)$ the steady state density was calculated for $\mathrm{O}\left({ }^{3} \mathrm{P}\right), \mathrm{O}_{2}\left(\mathrm{~b}^{1} \Sigma_{\mathrm{g}}^{+}\right), \mathrm{O}\left({ }^{1} \mathrm{D}\right), \mathrm{O}\left({ }^{1} \mathrm{~S}\right), \mathrm{O}_{3}, \mathrm{O}^{-}, \mathrm{O}_{2}^{-}$, and $\mathrm{O}_{3}^{-}$, respectively. The averaged density of negative ions $\mathrm{O}^{-}$from the rate equation calculation is compared with the measured one. The normalized source and loss rates are discussed for $\mathrm{O}\left({ }^{3} \mathrm{P}\right), \mathrm{O}_{2}\left(\mathrm{~b}^{1} \Sigma_{\mathrm{g}}^{+}\right)$and $\mathrm{O}^{-}$.
\end{abstract}

\section{Introduction}

Radio frequency (RF) plasmas at low pressure have been extensively investigated in experiment and modeling by many research groups over the past decades. In particular, progress was achieved in investigations of capacitively coupled RF plasmas (CCP), e.g., the dual or multi frequency RF plasmas [1-5] including consecutive harmonics for the electrical asymmetry effect [6-8] to control the plasma and reactive species density independently from the ion bombardment of the electrode in plasma surface processing, and the appearance of drift-ambipolar electric fields for electron heating in strongly electronegative plasmas [9]. Global/fluid models were applied for molecular CCP/ICP with large number of species [10-15], whereas the kinetic study of charged species in molecular RF plasmas was performed mostly by $1 \mathrm{~d} 3 \mathrm{v}$ particle in cell Monte Carlo collision (PIC-MCC) simulation of CCP [16-19]. The asymmetric $\mathrm{CCP}$ and ICP configuration needs multidimensional modeling/simulation, and in the case of ICP an electrodynamic approach. CCP and ICP have found manifold applications in plasma surface processing and materials science. The most important applications can be found in microelectronic manufac-

${ }^{a}$ Present address: Max-Planck-Institute for Plasma Physics, Wendelsteinstr. 1, 17491 Greifswald, Germany turing including plasma etching/cleaning of surfaces or thin film deposition. Other fields of applications involve the plasma surface functionalization of polymers, surface cleaning/disinfection, fabrication of thin functional films by plasma enhanced vapor deposition (PECVD), and the formation of nano- and microparticles. In particular, ICPs containing oxygen have been often applied in plasma surface processing [20-26].

Within the Collaborative Research Center 24 "Fundamentals of Complex Plasmas" the molecular and electronegative oxygen RF plasma $(13.56 \mathrm{MHz})$ was selected as a model system with capacitive and inductive RF power input (CCP, ICP) at low pressure. The challenge in investigation of oxygen plasmas concerns the manifold transient and stable oxygen species in combination with the study of electron heating mechanisms, mode transitions and the intrinsic plasma properties such as the electron energy distribution function and the charged species densities. The oxygen ICP has been intensively studied by comprehensive experimental diagnostics. Particularly, this concept follows the density determination of important plasma species (electrons, negative ions) and neutrals $\mathrm{O}_{2}\left(\mathrm{X}^{3} \Sigma_{\mathrm{g}}^{-}\right), \mathrm{O}_{2}\left(\mathrm{a}^{1} \Delta_{\mathrm{g}}\right)$ by line-integrated methods using Gaussian beam microwave interferometry (MWI) at $160 \mathrm{GHz}$ together with laser photodetachment and the VUV absorption spectroscopy (VUVA), respectively. The averaged densities calculated from line-integrated 
densities as well as the electron and gas temperature from experiment by Wegner et al. [27] are used as input parameter in volume averaged global model of steady state ICP at $13.56 \mathrm{MHz}$. Generally, the ICP starts at low RF power in the capacitive mode (E mode) and changes with increasing power in the inductive mode ( $\mathrm{H}$ mode). The $\mathrm{E}$ mode corresponds in principle to the CCP with electron heating in electric RF fields due to voltage drop between the coil windings, whereas in the $\mathrm{H}$ mode the electron heating takes place in the induced electric field from time-dependent magnetic field of the coil. Moreover, the direction of the induced electric field strength extends the electron confinement with the result of about two orders of magnitude higher plasma density compared with CCP. On the other hand, a very high electron density results in decreasing skin depth which reduces the penetration of the electromagnetic field and limits the region of electron heating and the plasma extension, respectively. During the E-H transition in ICP the electron heating mechanisms change, which is combined with alteration of plasma parameters, e.g., electron/gas temperature and species density. In the case of electronegative oxygen ICP the mode transition is combined with a change in the electronegativity, defined as the ratio between the negative ion and electron density.

In this paper the results are presented and discussed for the E-H transition in planar oxygen ICP due to combination of experimental results with analytical rate equation calculation of volume averaged global model. In section 2 and 3 the used RF discharge configuration for oxygen ICP at $13.56 \mathrm{MHz}$ is briefly described including the applied experimental diagnostics. Furthermore, the assumptions are given for the global model and the procedure is explained for the analytical rate equation calculation. The experimental data are presented in section 4 including the measured electron/gas temperature as well as the density of electrons, negative atomic oxygen ions $\mathrm{O}^{-}$, molecular ground state oxygen $\mathrm{O}_{2}\left(\mathrm{X}^{3} \Sigma_{\mathrm{g}}^{-}\right)$and metastable state oxygen $\mathrm{O}_{2}\left(\mathrm{a}^{1} \Delta_{\mathrm{g}}\right)$, respectively. In section 5 , the results of rate equation calculation are presented for the density of $\mathrm{O}\left({ }^{3} \mathrm{P}\right), \mathrm{O}_{2}\left(\mathrm{~b}^{1} \Sigma_{\mathrm{g}}^{+}\right)$ $\mathrm{O}\left({ }^{1} \mathrm{D}\right), \mathrm{O}\left({ }^{1} \mathrm{~S}\right), \mathrm{O}_{3}, \mathrm{O}^{-}, \mathrm{O}_{2}^{-}$, and $\mathrm{O}_{3}^{-}$whereupon the electron/gas temperature and the density of $\mathrm{O}_{2}\left(\mathrm{X}^{3} \Sigma_{\mathrm{g}}^{-}\right)$and $\mathrm{O}_{2}\left(\mathrm{a}^{1} \Delta_{\mathrm{g}}\right)$ are taken as input parameter in the global model. Furthermore, the calculated $\mathrm{O}^{-}$, density is compared with the measured one, and the source and loss rates are evaluated for $\mathrm{O}\left({ }^{3} \mathrm{P}\right), \mathrm{O}_{2}\left(\mathrm{~b}^{1} \Sigma_{\mathrm{g}}^{+}\right)$and $\mathrm{O}^{-}$.

\section{Experimental setup}

The experimental investigations were performed using a cylindrical stainless steel vacuum chamber $(400 \mathrm{~mm}$ in diameter and height), which was previously described by Dittmann et al. [28], see fig. 1. The vacuum chamber, which was on ground potential, is equipped with control units and pumps for low pressure plasma processing. The total chamber volume $V_{R}$ including the ports amounts to about 501 . The base pressure was set with a turbomolecular pump to less than $10^{-5} \mathrm{~Pa}$. During plasma processing, the total gas pressure $p$ was adjusted with a rotary vane pump in the range between 3 and $35 \mathrm{~Pa}$. The processing gas oxygen was inserted in the vacuum vessel with constant gas flow rate $Q$ of $5 \mathrm{sccm}$. The ICP discharge arrangement consists of a planar double spiral antenna with a diameter of about $100 \mathrm{~mm}$ and 2.75 windings [29], see fig. 1. The central connection of the antenna was powered using a $13.56 \mathrm{MHz} \mathrm{RF}$ power generator and a tunable matching network. The two opposite ends of the antenna were at ground potential. This antenna was installed in a quartz cylinder acting as dielectric barrier. A grounded stainless steel electrode was $50 \mathrm{~mm}$ apart from the bottom of the quartz cylinder. The power variation between 1 and $600 \mathrm{~W}$ yielded to a (peak-to-peak) coil voltage between $1 \mathrm{kV}$ and $9 \mathrm{kV}$ and a (peak-to-peak) coil current between $10 \mathrm{~A}$ and $50 \mathrm{~A}$. The matching network in the discharge configurations was set to achieve a minimum reflected RF power. Furthermore, it was fixed in the power region where a mode transition was observed to exclude its influence on the discharge parameters.

An enhanced set of plasma diagnostics were applied to analyze the plasma parameters, electronegativity, electron heating mechanisms as well as density of neutral oxygen species $\mathrm{O}_{2}\left(\mathrm{X}^{3} \Sigma_{\mathrm{g}}^{-}\right)$and $\mathrm{O}_{2}\left(\mathrm{a}^{1} \Delta_{\mathrm{g}}\right)$ during the E-H transition in dependence on RF power/voltage and pressure. In the following, the used diagnostics are shortly described whereas a detailed description can be found in the given references. A cylindrical Langmuir probe was used for spatially resolved measurements of plasma parameters, e.g., positive ion saturation current and (effective) electron temperature. The experimental setup of the Langmuir probe measurement and the analysis of the characteristics have been explained by Küllig et al. [30] and Wegner et al. [31]. A non-invasive $160 \mathrm{GHz}$ Gaussian beam microwave interferometer was installed to measure the line-integrated electron density with a high time resolution of about $200 \mathrm{~ns}$ [28]. Without any model assumption, the line-integrated electron density can be determined by measuring the phase shift between the plasma-on and -off phase. The density of negative oxygen ions was measured for the determination of the electronegativity. This was realized by measuring the released electrons by microwave interferometry after the laser photodetachment of negative ions $[32,33]$. The photon energy and intensity of the Nd:YAG laser at $532 \mathrm{~nm}$ is sufficiently high to detach electrons from $\mathrm{O}^{-}$(and $\mathrm{O}_{2}^{-}, \mathrm{O}_{3}^{-}$). Additionally, an electron density peak was measured in the early afterglow of pulsed oxygen ICP due to collision detachment of negative atomic oxygen ions by molecular metastables which provides the negative ion density, too $[33,34]$.

The plasma-induced optical emission of molecular oxygen at $760 \mathrm{~nm}$ (atmospheric A-band, $\mathrm{O}_{2}\left(\mathrm{~b}^{1} \Sigma_{\mathrm{g}}^{+}, v=0\right) \longrightarrow \mathrm{O}_{2}\left(\mathrm{X}^{3} \Sigma_{\mathrm{g}}^{-}, v=\right.$ $0)$ ), [35], was evaluated and the rotational temperature was determined from the Boltzmann plot. The rotational temperature was assumed to be comparable to gas temperature in the active plasma region in the used total pressure range. The setup and the analysis have been explained by Wegner et al. [27]. The electron heating mechanisms in oxygen plasma were studied by space and phase resolved optical emission spectroscopy (PROES), which has been explained by Dittmann et al. [17]. Here, the emission intensity of oxygen at $844 \mathrm{~nm}$ was measured by an intensified charge coupled device (ICCD) via bandpass filter, which enabled an effective time resolution of about $1 \mathrm{~ns}$ and resulted in 74 radially averaged images for one RF cycle. Taking into account the natural lifetime and the collision deexcitation of the initial state the relative excitation rate was cal- 


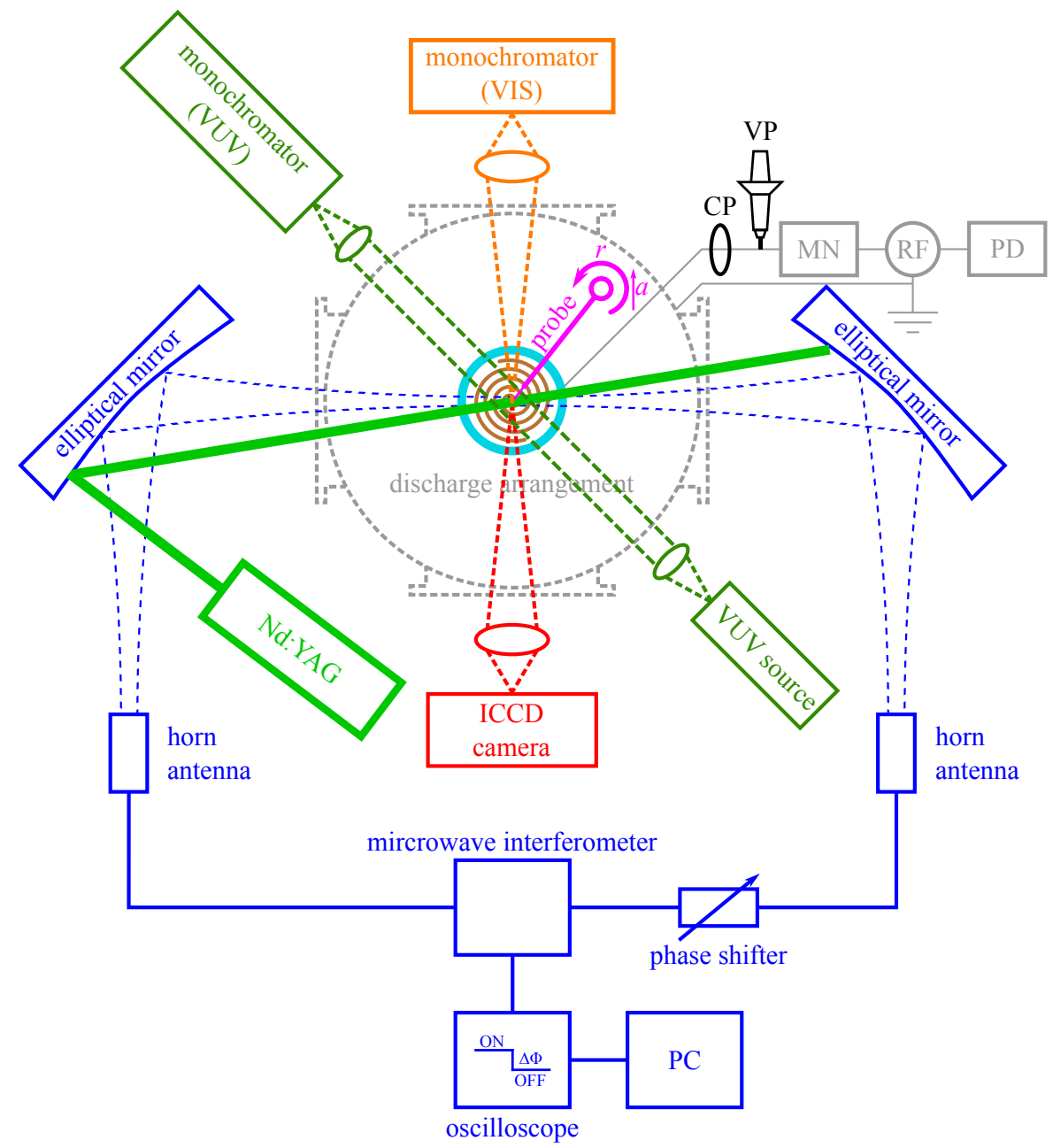

Fig. 1. Schematic top view of the discharge chamber with the gas supply, power supply (RF), matching network (MN) and pulse delay generator (PD). The plasma diagnostics involves voltage (VP) and current (CP) probes, the axially $(a)$ and radially $(r)$ movable Langmuir probe, the $160 \mathrm{GHz}$ microwave interferometer, the Nd:YAG laser at $532 \mathrm{~nm}$, the ICCD camera and two monochromators for the optical emission (VIS) and absorption (VUV) spectroscopy, respectively.

culated to have clear separation of the electron heating mechanisms, [36]. Finally, the vacuum ultraviolet (VUV) absorption spectroscopy was applied to determine the line-integrated molecular ground state $\mathrm{O}_{2}\left(\mathrm{X}^{3} \Sigma_{\mathrm{g}}^{-}\right)$and the singlet molecular metastable $\mathrm{O}_{2}\left(\mathrm{a}^{1} \Delta_{\mathrm{g}}\right)$ density [27]. Here, a deuterium lamp emits in the appropriate VUV wavelength range and the transmitted intensity was analyzed by VUV monochromator comparing the intensity with and without plasma. Absolute densities were calculated from the measured line-integrated densities by averaging over the line of sight across the vacuum chamber for $\mathrm{O}_{2}\left(\mathrm{X}^{3} \Sigma_{\mathrm{g}}^{-}\right)$and $\mathrm{O}_{2}\left(\mathrm{a}^{1} \Delta_{\mathrm{g}}\right)$ and in the case of electrons over the radial plasma density distribution from Langmuir probe measurements along the microwave line of sight, respectively.

\section{Volume averaged global model}

A volume averaged global model was applied for the steady state oxygen ICP to calculate analytically the averaged number density of further oxygen species during the E-H mode transition. The analytical calculations were performed taking into account the measured (effective) electron temperature and the gas temperature as well as the averaged density from lineintegrated measurements of electrons, ground state oxygen molecules $\mathrm{O}_{2}\left(\mathrm{X}^{3} \Sigma_{\mathrm{g}}^{-}\right)$and metastable oxygen molecules $\mathrm{O}_{2}\left(\mathrm{a}^{1} \Delta_{\mathrm{g}}\right)$, respectively, [27,33]. The density of the positive oxygen ions was determined by the quasi neutrality relation $n_{\mathrm{O}_{2}^{+}}+n_{\mathrm{O}^{+}}=$ $n_{\mathrm{e}}+n_{\mathrm{O}^{-}}+n_{\mathrm{O}_{2}^{-}}+n_{\mathrm{O}_{3}^{-}}$during the calculation of the rate equation system. Here, it was used a ratio of $n_{\mathrm{O}_{2}^{+}} / n_{\mathrm{O}^{+}}=85 / 15$ between the positive molecular oxygen ion density $\mathrm{O}_{2}^{+}$and the atomic oxygen ion density $\mathrm{O}^{+}$. This fraction was estimated from extracted positive oxygen ions in oxygen $\mathrm{CCP}$ by energy resolved ion mass spectrometry [37]. In particular, the volume averaged global model is used to determine the averaged density of $\mathrm{O}\left({ }^{3} \mathrm{P}\right), \mathrm{O}_{2}\left(\mathrm{~b}^{1} \Sigma_{\mathrm{g}}^{+}\right), \mathrm{O}\left({ }^{1} \mathrm{D}\right), \mathrm{O}\left({ }^{1} \mathrm{~S}\right), \mathrm{O}_{3}, \mathrm{O}^{-}, \mathrm{O}_{2}^{-}$, and $\mathrm{O}_{3}^{-}$during the E-H mode transition. According to the applied vacuum chamber and ICP configuration, see fig.1, a small active plasma volume $V_{\mathrm{P}} \approx 0.5 l$ is inside a large chamber volume $V_{\mathrm{R}} \approx 50 l$ with an effective internal stainless steel surface $A_{\mathrm{R}} \approx 1 \mathrm{~m}^{2}$. At the used low pressure a fast diffusion exchange of the neutrals between the plasma volume and the large sur- 
rounding buffer volume can be assumed (diffusion time constant $\tau_{\mathrm{D}} \approx 10^{-3}-10^{-2} \mathrm{~s}$ ). Considering the used total gas pressure of $5 \mathrm{~Pa}$ at low oxygen gas flow rate $Q=5 \mathrm{sccm}$ (input) the mean gas residence time in the vacuum chamber $\tau_{\mathrm{Q}}=$ $p \cdot V_{\mathrm{R}} \cdot Q^{-1} \approx 30 \mathrm{~s}$ is more than three orders of magnitude higher compared with diffusion time. That means a plasma chemical back-mixing reactor is taken into account including an effective loss rate for reactive and metastable neutrals at the internal stainless steel surface of the vacuum chamber. The following rate equations (1) - (8) are involved in the global model. Here, the reaction rates which involve electrons and/or oxygen ions have to be taken into consideration for the plasma volume $V_{\mathrm{P}}$, only. This is realized by multiplication of the corresponding reaction rate with the fraction $\eta=V_{\mathrm{P}} / V_{\mathrm{R}} \approx 0.01$. The implemented elementary processes and the necessary rate coefficients from literature are listed in table1.

$$
\begin{aligned}
& \frac{\mathrm{d}}{\mathrm{d} t} n_{\mathrm{O}(\mathrm{D})}=0= \\
& \eta \cdot\left[\left(k_{2}+2 k_{3}\right) n_{\mathrm{O} 2(\mathrm{X})}+\left(k_{10}+k_{12}\right) n_{\mathrm{O} 2(\mathrm{a})}+k_{19} n_{\mathrm{O} 2(\mathrm{~b})}\right. \\
& \left.+k_{21} n_{\mathrm{O}}+k_{27} n_{\mathrm{O}+}+\left(k_{28}+2 k_{29}\right) n_{\mathrm{O} 2+}\right] n_{\mathrm{e}} \\
& +\eta \cdot k_{58} n_{\mathrm{O}-} n_{\mathrm{O}+}+\left(k_{69} n_{\mathrm{O}}+k_{75} n_{\mathrm{O} 2(\mathrm{a})}+k_{80} n_{\mathrm{O} 2(\mathrm{X})}\right) n_{\mathrm{O}(\mathrm{S})} \\
& +k_{99} n_{\mathrm{O} 3} n_{\mathrm{O} 2(\mathrm{a})} \\
& -\left[\eta \cdot\left[\left(k_{24}+k_{25}\right) n_{\mathrm{e}}+k_{37} n_{\mathrm{O} 2+}\right]+k_{67} n_{\mathrm{O}}+\left(k_{76}+k_{77}+k_{78}\right) n_{\mathrm{O} 2(\mathrm{X})}\right. \\
& \left.+\left(k_{92}+k_{93}+k_{94}+k_{95}\right) n_{\mathrm{O} 3}+k_{\mathrm{wall}}^{\mathrm{quen}}+k_{\mathrm{wall}}^{\mathrm{rec}}+k_{\mathrm{pump}}\right] n_{\mathrm{O}(\mathrm{D})} \\
& \frac{\mathrm{d}}{\mathrm{d} t} n_{\mathrm{O}(\mathrm{S})}=0= \\
& +\eta \cdot k_{22} n_{\mathrm{O}} n_{\mathrm{e}} \\
& -\left[\eta \cdot k_{26} n_{\mathrm{e}}+\left(k_{68}+k_{69}\right) n_{\mathrm{O}}+\left(k_{79}+k_{80}\right) n_{\mathrm{O} 2(\mathrm{X})}+\left(k_{73}+k_{74}+\right.\right. \\
& \left.\left.+k_{75}\right) n_{\mathrm{O} 2(\mathrm{a})}+k_{96} n_{\mathrm{O} 3}+k_{\mathrm{wall}}^{\text {quen }}+k_{\mathrm{wall}}^{\mathrm{rec}}+k_{\mathrm{pump}}\right] n_{\mathrm{O}(\mathrm{S})}
\end{aligned}
$$

$$
\begin{aligned}
& \frac{\mathrm{d}}{\mathrm{d} t} n_{\mathrm{O} 3}=0= \\
& +\eta \cdot\left[\left(k_{41} n_{\mathrm{O}-}+k_{56} n_{\mathrm{O} 3-}\right) n_{\mathrm{O} 2(\mathrm{X})}+k_{43} n_{\mathrm{O}-} n_{\mathrm{O} 2(\mathrm{a})}+k_{49} n_{\mathrm{O} 2-} n_{\mathrm{O}}\right. \\
& \left.+\left(k_{64}+k_{65}\right) n_{\mathrm{O} 2+} n_{\mathrm{O} 3-}+k_{66} n_{\mathrm{O}+} n_{\mathrm{O} 3-}\right]+k_{81} n_{\mathrm{O} 2 / \mathrm{X})} n_{\mathrm{O} 2(\mathrm{a})} \\
& -\left[\eta \cdot \left[\left(k_{31}+k_{32}+k_{33}\right) n_{\mathrm{e}}+k_{36} n_{\mathrm{O}+}+\left(k_{45}+k_{46}+k_{47}\right) n_{\mathrm{O}-}\right.\right. \\
& \left.+k_{53} n_{\mathrm{O} 2-}\right]+\left(k_{88}+k_{89}+k_{90}+k_{91}\right) n_{\mathrm{O}}+\left(k_{93}+k_{94}+k_{95}\right) n_{\mathrm{O}(\mathrm{D})} \\
& +k_{96} n_{\mathrm{O}(\mathrm{S})}+k_{97} n_{\mathrm{O} 2(\mathrm{X})}+\left(k_{98}+k_{99}+k_{100}\right) n_{\mathrm{O} 2(\mathrm{a})} \\
& \left.+\left(k_{101}+k_{102}+k_{103}\right) n_{\mathrm{O} 2(\mathrm{~b})}+0.5 \cdot k_{104} n_{\mathrm{O} 3}+k_{\mathrm{wall}}^{\mathrm{prod}}+k_{\mathrm{pump}}\right] n_{\mathrm{O} 3}
\end{aligned}
$$

$$
\begin{aligned}
& \frac{\mathrm{d}}{\mathrm{d} t} n_{\mathrm{O}-}=0= \\
& +\eta \cdot\left[\left[\left(k_{5}+k_{6}\right) n_{\mathrm{O} 2(\mathrm{X})}+\left(k_{11}+k_{12}\right) n_{\mathrm{O} 2(\mathrm{a})}+k_{16} n_{\mathrm{O} 2(\mathrm{~b})}+k_{32} n_{\mathrm{O} 3}\right] n_{\mathrm{e}}\right. \\
& \left.+k_{48} n_{\mathrm{O} 2-} n_{\mathrm{O}}\right] \\
& -\eta \cdot\left[k_{30} n_{\mathrm{e}}+k_{38} n_{\mathrm{O}}+\left(k_{39}+k_{41}\right) n_{\mathrm{O} 2(\mathrm{X})}+\left(k_{42}+k_{43}\right) n_{\mathrm{O} 2(\mathrm{a})}\right. \\
& \left.+\left(k_{45}+k_{46}+k_{47}\right) n_{\mathrm{O} 3}+\left(k_{57}+k_{58}\right) n_{\mathrm{O}+}+\left(k_{59}+k_{60}\right) n_{\mathrm{O} 2+}\right] n_{\mathrm{O}-}
\end{aligned}
$$

$$
\begin{aligned}
& \frac{\mathrm{d}}{\mathrm{d} t} n_{\mathrm{O} 2-}=0= \\
& +\eta \cdot\left[\left(k_{42} n_{\mathrm{O} 2(\mathrm{a})}+k_{47} n_{\mathrm{O} 3}\right) n_{\mathrm{O}-}+k_{33} n_{\mathrm{e}} n_{\mathrm{O} 3}+k_{54} n_{\mathrm{O}} n_{\mathrm{O} 3-}\right] \\
& -\eta \cdot\left[\left(k_{48}+k_{49}\right) n_{\mathrm{O}}+k_{50} n_{\mathrm{O} 2(\mathrm{X})}+k_{51} n_{\mathrm{O} 2(\mathrm{a})}+k_{52} n_{\mathrm{O} 2(\mathrm{~b})}+k_{53} n_{\mathrm{O} 3}\right. \\
& \left.+k_{61} n_{\mathrm{O}+}+\left(k_{62}+k_{63}\right) n_{\mathrm{O} 2+}\right] n_{\mathrm{O} 2-}
\end{aligned}
$$

$$
\begin{aligned}
& \frac{\mathrm{d}}{\mathrm{d} t} n_{\mathrm{O} 3-}=0= \\
& +\eta \cdot\left[\left(k_{46} n_{\mathrm{O}-}+k_{53} n_{\mathrm{O} 2-}\right) n_{\mathrm{O} 3}\right. \\
& -\eta \cdot\left[\left(k_{54}+k_{55}\right) n_{\mathrm{O}}+k_{56} n_{\mathrm{O} 2(\mathrm{X})}+\left(k_{64}+k_{65}\right) n_{\mathrm{O} 2+}+k_{66} n_{\mathrm{O}+}\right] n_{\mathrm{O} 3-}
\end{aligned}
$$




$$
\begin{gathered}
k_{\text {wall }}=\frac{<v_{\text {th }}>\cdot \gamma}{2 \cdot(2-\gamma)} \cdot \frac{A_{\mathrm{R}}}{V_{\mathrm{R}}} \\
k_{\text {pump }} \approx k_{\mathrm{Q}}=\frac{1}{\tau_{\mathrm{Q}}}=\frac{Q}{p \cdot V_{\mathrm{R}}}
\end{gathered}
$$

Vibrationally excited oxygen molecules and Herzberg states were not considered in the calculation. The effective loss processes at the surface are included according to (9) involving the total chamber volume $V_{\mathrm{R}}$, the effective size of the internal reactor surface $A_{\mathrm{R}}$, the effective sticking coefficient $\gamma$ and the mean thermal velocity $\left\langle v_{\text {th }}>\right.$ for the different neutrals with the measured gas temperature, $[38,39]$. The gas temperature in the surrounding volume and the internal wall temperature were not measured. In the experiment the external wall temperature was estimated during the E-H transition from room temperature to about $330 \mathrm{~K}$. The variation in the thermal velocity due to temperature gradients in the processing gas is in the order of $\sqrt{2}$ in maximum comparing the $\mathrm{E}$ and $\mathrm{H}$ mode. Here, a critical point is to find the right sticking coefficient $\gamma$ for the highly reactive interaction of atomic oxygen with stainless steel surface. Unfortunately, the values are found for the sticking coefficient of atomic oxygen in the literature ranging between $0.1<\gamma_{O}<1[40,41]$. In particular, the sticking coefficient was experimentally determined in the range $0.1<\gamma_{\mathrm{O}}<0.8$ by two-photon laser induced fluorescence (TALIF) of atomic oxygen, [42], or $\gamma_{\mathrm{O}} \approx 0.17$ by mass spectrometry, [39]. Gudmundsson [43] and Toneli [15] used for the sticking coefficient of ground state atomic oxygen a formula by fitting experimental data in the pressure range between 2 and 150 mTorr $(0.3$ - $20 \mathrm{~Pa}) \gamma_{\mathrm{O}}=0.1438 \cdot \exp (2.5069 / p[\mathrm{mTorr}])$. In our calculations the corresponding effective sticking coefficient was taken into account for ground state atomic oxygen $\mathrm{O}\left({ }^{3} \mathrm{P}\right)$ on stainless steel $\gamma_{\mathrm{O}}=0.154$ and $\gamma_{\mathrm{O}}=0.1487$ for $5 \mathrm{~Pa}$ and $10 \mathrm{~Pa}$, respectively. For the metastable molecular oxygen $\mathrm{O}_{2}\left(\mathrm{~b}^{1} \Sigma_{\mathrm{g}}^{+}\right)$ the sticking coefficient $\gamma_{\mathrm{O}_{2}(\mathrm{~b})}=0.007$ [10],[43] was applied. To show their influence on the calculated averaged density of oxygen species, a larger sticking coefficient $\gamma_{\mathrm{O}_{2}(\mathrm{~b})}=0.1$ [15] was considered, too. In the case of both singlet atomic oxygen $\mathrm{O}\left({ }^{1} \mathrm{D}\right)$ and $\mathrm{O}\left({ }^{1} \mathrm{~S}\right)$ it was set the surface sticking coefficient $\gamma_{\mathrm{O}(\mathrm{D})}=\gamma_{\mathrm{O}(\mathrm{S})}=1=0.5$ (quen) +0.5 (rec) [44],[45] considering quenching and recombination, separately. The sticking coefficient for ozone $\mathrm{O}_{3}$ was assumed $\gamma_{\mathrm{O}_{3}}=0.001$. Due to the confinement of negative ions in the plasma region, no loss processes were considered due to diffusion and pumping.

The rate equation system (1) - (8) was solved analytically by iteration procedure using appropriate initial densities for the considered unknown species. Here, the equalized balances were examined for the total source and loss rate as control parameter in the order of $10^{-5}$ for each species.

\section{Experimental results}

This chapter summarizes the main experimental results from the investigation of the E-H transition in oxygen ICP at low

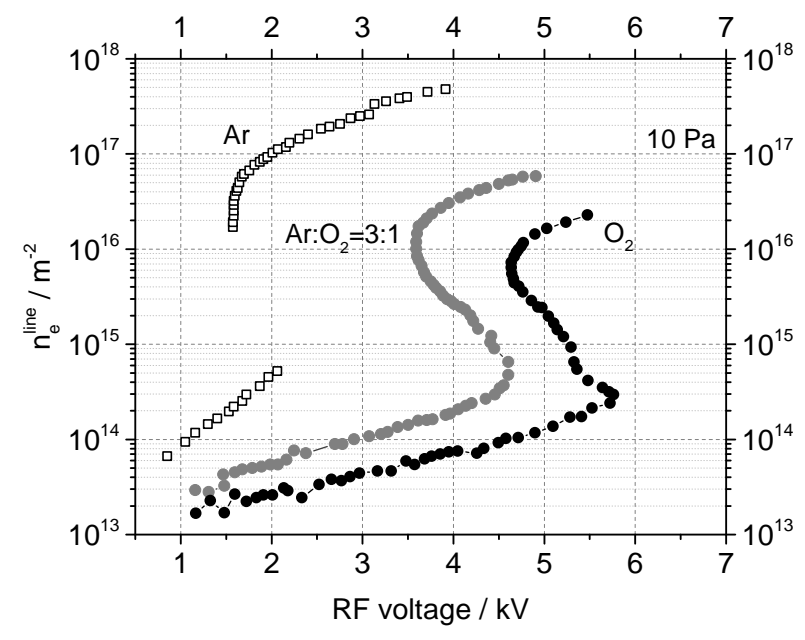

Fig. 2. Line-integrated electron density vs. $\mathrm{RF}$ voltage in $\mathrm{Ar}, \mathrm{O}_{2}$, and $\mathrm{Ar} / \mathrm{O}_{2}(3 / 1)$ for total pressure of $10 \mathrm{~Pa}$ during the $\mathrm{E}-\mathrm{H}$ transition. Data are taken from [27].

pressure [27,33]. Fig. 2 presents exemplarily the measured lineintegrated electron density for pure argon and oxygen, respectively, as well as for a mixture of $25 \%$ oxygen and $75 \%$ argon, whereas fig. 3 shows the averaged electron density along the microwave line of sight in pure oxygen for three total pressures. The electron density is plotted vs. RF voltage to see clearer the separation between the $\mathrm{E}$ and $\mathrm{H}$ mode. In these experiments the RF forward power ranges between about 2 and $475 \mathrm{~W}$. The positive ion saturation current vs. RF voltage changes in a similar way as the averaged electron density during E-H transition [29]. Summarized, the electron density increases about 3 orders of magnitude from about $10^{14} \mathrm{~m}^{-3}$ in the $\mathrm{E}$ mode to $10^{17} \mathrm{~m}^{-3}$ in the $\mathrm{H}$ mode. Surprisingly, a continuous E-H transition appears for the electron density, see figs. 2 and 3, as well as for the positive ion saturation current in oxygen ICP at a total pressure lower than about $35 \mathrm{~Pa}$ [31]. This E-H transition with continuously increasing electron density was analyzed in comparison with the phase resolved optical emission spectroscopy (PROES). From the emission of atomic oxygen at $844 \mathrm{~nm}$ the relative excitation rate pattern was calculated and is presented in fig. 4, [31]. The discharge starts with low electron density in the $\mathrm{E}$ mode and the electron density increases weakly with raising RF voltage. In fig. 4 at position (a), a weak (I) and intense (II) excitation rate pattern appears, respectively, assigned to electron heating during the RF sheath expansion phase (I) and the electric field reversal (II) during the sheath collapse phase. The excitation rate pattern (II) is an indication for strongly electronegative plasmas. That means a driftambipolar electric field appears at low electron density to balance the charge transport by electrons over the RF cycle. With increasing RF voltage (and RF power), the pattern (I) due to RF sheath heating of electrons during the sheath expansion phase is intensified and the pattern from electric field reversal (I) disappears, compare positions (a), (b) and (c) in fig. 4. With stronger increasing electron density, a hybrid mode or $\mathrm{E} / \mathrm{H}$ mode was observed in which capacitive and inductive heating appear simultaneously. In particular, the typical excitation rate pattern 
from the capacitive electron heating (I) overlaps in the first half of the RF cycle with the new excitation rate pattern (III) from the inductive electron heating, see position (d) in fig. 4. In the second half of the RF cycle the inductive heating is present, only. In the $\mathrm{H}$ mode two excitation rate patterns (III) appear per RF cycle due to inductive electron heating, see position (e) in fig. 4. The change of the electron and gas temperature vs. electron density is shown in figs. 5 and 6 during the E-H transition, respectively. The electron temperature was determined from Langmuir probe measurements taking into calculation the mean electron energy from the electron energy distribution in the $\mathrm{E}$ mode for an effective electron temperature, whereas in the $\mathrm{H}$ mode a Maxwellian electron energy distribution function exists with a corresponding electron temperature, [27]. The (effective) electron temperature of about $6.5 \mathrm{eV}$ in the $\mathrm{E}$ mode is almost halved during transition from the $\mathrm{E}$ mode to the hybrid $(\mathrm{E} / \mathrm{H})$ mode and remains at this level until the $\mathrm{H}$ mode. The gas temperature is near room temperature in the $\mathrm{E}$ mode and increases continuously from about $325 \mathrm{~K}$ in the hybrid $(\mathrm{E} / \mathrm{H})$ mode to about $600 \mathrm{~K}$ in the $\mathrm{H}$ mode.

The averaged value of the negative ion density $\left(\mathrm{O}^{-}\right)$from laser photodetachment and the collision detachment in the early afterglow is presented vs. electron density in fig. 7 for $5 \mathrm{~Pa}$ and $10 \mathrm{~Pa}$ total pressure, respectively. The averaged negative ion density increases continuously over about one order of magnitude from about $10^{15} \mathrm{~m}^{-3}$ to $10^{16} \mathrm{~m}^{-3}$ with raising electron density during the E-H transition. Here, the electronegativity $\alpha$, defined as the ratio between negative ion and electron density, reveals a decreasing electronegativity from $\mathrm{E}$ to $\mathrm{H}$ mode and is in agreement with the disappearing excitation rate pattern (II) in the E mode, see fig. 4 (a-c).

Furthermore, the line-integrated densities of the molecular ground state $\mathrm{O}_{2}\left(\mathrm{X}^{3} \Sigma_{\mathrm{g}}^{-}\right)$and singlet metastable state $\mathrm{O}_{2}\left(\mathrm{a}^{1} \Delta_{\mathrm{g}}\right)$ were measured by VUV absorption spectroscopy, [27]. These line-integrated densities were converted in averaged densities using an effective absorption length across the vacuum chamber, see fig. 8. The density of the measured neutral oxygen

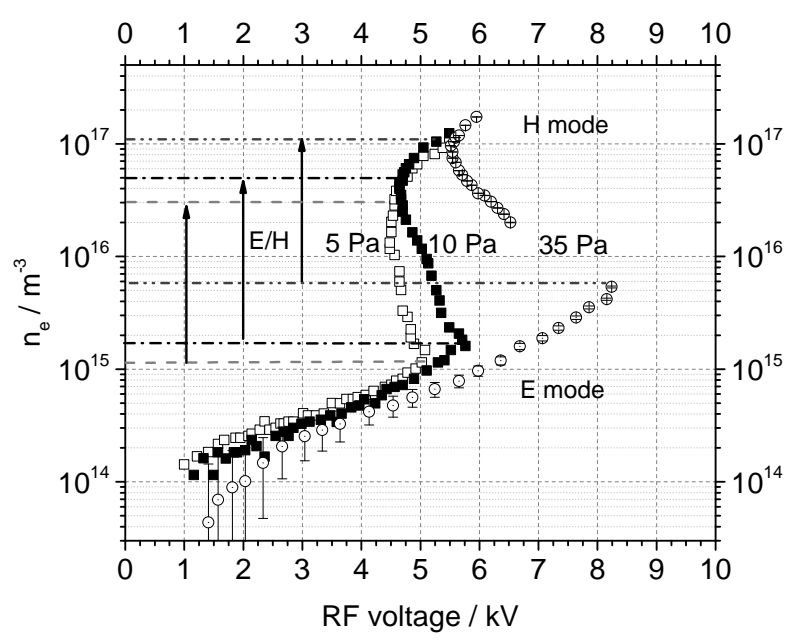

Fig. 3. Averaged electron density vs. RF voltage in $\mathrm{O}_{2}$ for total pressure of $5 \mathrm{~Pa}, 10 \mathrm{~Pa}$, and $35 \mathrm{~Pa}$ during the E-H transition. Data are taken from [27]. molecules changes weakly in the $\mathrm{E}$ and $\mathrm{E} / \mathrm{H}$ mode, whereupon a density reduction by factor of 2 is observed from $\mathrm{E} / \mathrm{H}$ mode towards the $\mathrm{H}$ mode due to increasing gas temperature and dissociation.

\section{Global model, results of analytical rate equation calculation}

The results of rate equation calculations are presented for the $\mathrm{O}\left({ }^{3} \mathrm{P}\right)$ and $\mathrm{O}_{2}\left(\mathrm{~b}^{1} \Sigma_{\mathrm{g}}^{+}\right)$density vs. electron density during the E$\mathrm{H}$ mode transition in fig. 9 (a), (b) together with the measured $\mathrm{O}_{2}\left(\mathrm{X}^{3} \Sigma_{\mathrm{g}}^{-}\right)$and $\mathrm{O}_{2}\left(\mathrm{a}^{1} \Delta_{\mathrm{g}}\right)$ density at total pressure of $5 \mathrm{~Pa}$ and $10 \mathrm{~Pa}$, respectively. Both calculated densities reveal the same qualitative behavior and raise more than one order of magnitude during the E-H transition. For the sticking coefficient $\gamma_{\mathrm{O} 2(\mathrm{~b})}=0.007$ the $\mathrm{O}_{2}\left(\mathrm{~b}^{1} \Sigma_{\mathrm{g}}^{+}\right)$density exceeds the $\mathrm{O}_{2}\left(\mathrm{a}^{1} \Delta_{\mathrm{g}}\right)$ density in the $\mathrm{H}$ mode. Using $\gamma_{\mathrm{O} 2(\mathrm{~b})}=0.1$ the $\mathrm{O}_{2}\left(\mathrm{~b}^{1} \Sigma_{\mathrm{g}}^{+}\right)$density is reduced by about one order of magnitude while no significant changes are observed for the $\mathrm{O}\left({ }^{3} \mathrm{P}\right)$ density.

Experimental data from oxygen ICP at 25 mTorr by Corr et al. [11] show similar behavior for the $\mathrm{O}\left({ }^{3} \mathrm{P}\right)$ density during the E-H mode transition. The density of the atomic metastables $\mathrm{O}\left({ }^{1} \mathrm{D}\right)$ and $\mathrm{O}\left({ }^{1} \mathrm{~S}\right)$ in fig. $10(\mathrm{a})$ increases during the E-H transition in similar way as $\mathrm{O}\left({ }^{3} \mathrm{P}\right)$ in fig. 9 (a), but the $\mathrm{O}\left({ }^{1} \mathrm{D}\right)$ density is about two orders of magnitude lower than the $\mathrm{O}\left({ }^{3} \mathrm{P}\right)$ density, whereas the $\mathrm{O}\left({ }^{1} \mathrm{~S}\right)$ density is more than five orders of magnitude lower, respectively. It should be noted, that in the rate equation for $\mathrm{O}\left({ }^{1} \mathrm{~S}\right)$ the reaction $R_{20}$ was not considered as an additional source due to missing rate coefficient. The ozone density was found in the order of $10^{14} \mathrm{~m}^{-3}$. This density raises about one order of magnitude in the $\mathrm{H}$ mode by use of the sticking coefficient $\gamma_{\mathrm{O} 2(\mathrm{~b})}=0.1$, see fig. 10 (a).

The calculated density of $\mathrm{O}^{-}, \mathrm{O}_{2}^{-}$and $\mathrm{O}_{3}^{-}$in fig. 10 (b) reveals significant differences as expected. The dominant negative ion is the atomic negative ion $\mathrm{O}^{-}$. The density of molecular negative ions compared with $\mathrm{O}^{-}$is clearly reduced by about two orders of magnitude for $\mathrm{O}_{2}^{-}$and about six orders of magnitude for $\mathrm{O}_{3}^{-}$, respectively. The measured $\mathrm{O}^{-}$density increases about one order of magnitude during the $\mathrm{E}-\mathrm{H}$ transition, whereupon the electron density raises about three orders of magnitude, respectively. Comparing the experimentally determined negative ion density with the calculated $\mathrm{O}^{-}$density, the calculated density is underestimated in the E mode and overestimated in the $\mathrm{H}$ mode. In the experiment the electron and the negative ion density due to released electrons were measured by Gaussian beam microwave interferometry with a fixed position of the line of sight. In particular, the spatial distribution of the electrons and negative ions may change in axial direction during the E-H transition, which is a disadvantage for the used global model. Nevertheless, the calculated density of the negative atomic oxygen ion distinguishes by a factor of about 2 in comparison with the experiment. Taking into consideration the rate coefficients for electron impact oxygen dissociation in Gudmundsson and Thorsteinsson [43] the rate equation calculations are performed to show their influence on our calculated neutral densities with the rate coefficients by Gudmundsson [46], see fig.11. In result the neutral density of $\mathrm{O}\left({ }^{3} \mathrm{P}\right), \mathrm{O}_{2}\left(\mathrm{~b}^{1} \Sigma_{\mathrm{g}}^{+}\right), \mathrm{O}\left({ }^{1} \mathrm{D}\right)$, and $\mathrm{O}\left({ }^{1} \mathrm{~S}\right)$ shows the same qualitative behavior during the E-H mode tran- 

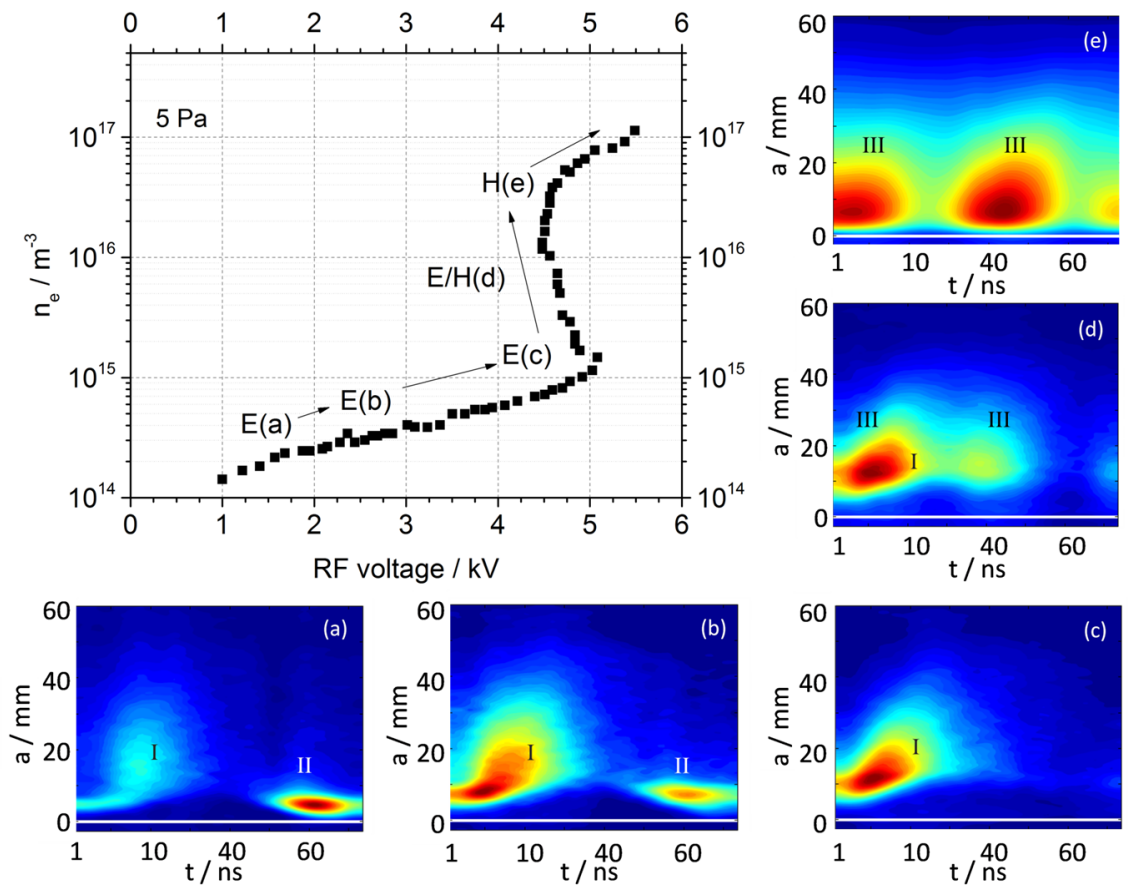

Fig. 4. Electron density vs. RF voltage in oxygen ICP during the E-H transition in relation to the excitation rate patterns (844 $\mathrm{nm})$ in axial direction ( $a=0$ : quartz plate) over one RF cycle. (a) E mode with dominant pattern (II) due to electric field reversal at sheath collapse phase; (b) E mode with dominant pattern (I) due to RF sheath heating and reduced field reversal (II); (c) E mode with pattern due to RF sheath heating (I); (d) Hybrid (E/H) mode with sheath heating pattern (I) and overlapping pattern from inductive heating (III); (e) Complete H mode with two inductive heating patterns (III) per RF cycle. Data are taken from [27,31].

sition but the corresponding densities are reduced by one order of magnitude. The density of $\mathrm{O}_{3}$ increases by about one order of magnitude in the $\mathrm{E}-\mathrm{H}$ and $\mathrm{H}$ mode.

The Behavior of the atomic negative ion $\mathrm{O}^{-}$is discussed more in detail using fig. 12 (a). Taking into calculation the sticking coefficient $\gamma_{\mathrm{O} 2(\mathrm{~b})}=0.1$ or the reduced dissociation rates for $\mathrm{O}_{2}\left(\mathrm{X}^{3} \Sigma_{\mathrm{g}}^{-}\right)$and $\mathrm{O}_{2}\left(\mathrm{a}^{1} \Delta_{\mathrm{g}}\right)$ used in [43], nearly the same result

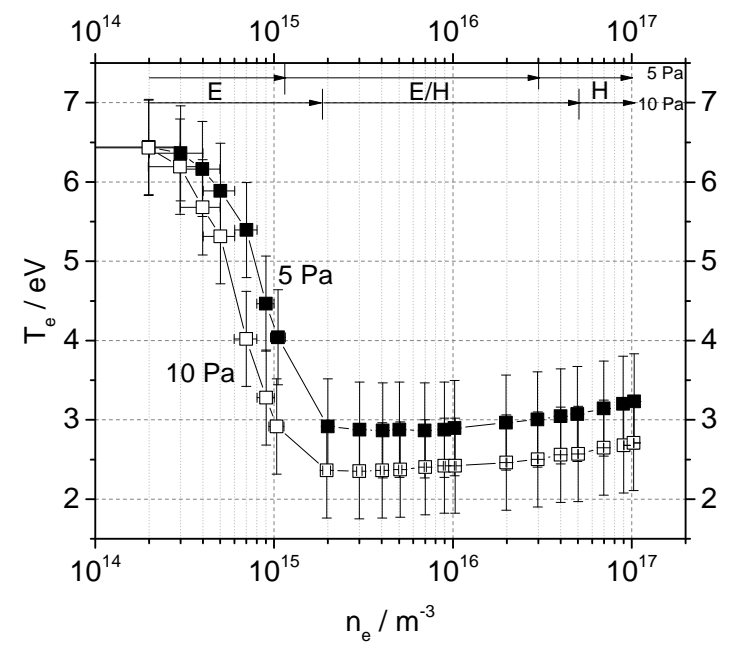

Fig. 5. Decreasing electron temperature vs. electron density during $\mathrm{E}-\mathrm{H}$ transition at $5 \mathrm{~Pa}$ and $10 \mathrm{~Pa}$. Data are taken from [27].

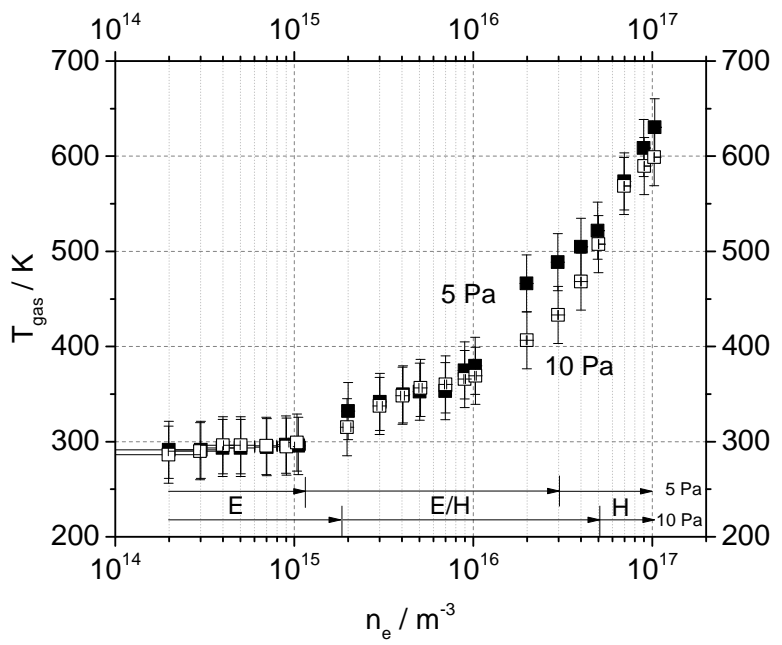

Fig. 6. Increasing gas temperature vs. electron density during E-H transition at $5 \mathrm{~Pa}$ and $10 \mathrm{~Pa}$. Data are taken from [27].

was achieved for the atomic negative ion density $\mathrm{O}^{-}$during the E-H mode transition. This density is more than half order of magnitude higher compared with the measured negative ion density and by a factor of 2 higher compared with the calculated density using $\gamma_{\mathrm{O} 2(\mathrm{~b})}=0.007$ in the $\mathrm{E}-\mathrm{H}$ and $\mathrm{H}$ mode, respectively. The corresponding electronegativity $\alpha=n_{\mathrm{O}^{-}} / n_{\mathrm{e}}$ is determined from the measured and calculated $\mathrm{O}^{-}$density, see 
fig. 12 (b). The difference between $\alpha_{\text {exp }}$ and $\alpha_{\text {cal }}$ corresponds with the deviations between the measured and calculated negative ion density in fig.12 (a). Considering the noise band in microwave interferometry of about $2 \times 10^{14} \mathrm{~m}^{-3}$ for the measured electron density, the error in the measured electron density has more influence on the electronegativity determination from experimental data at low electron density in the E mode. This can contribute to an overestimation of the electronegativity in the experiment.

The total particle balance in the global model is checked by the total pressure calculated from the neutral densities and the gas temperature for the used pressure of $5 \mathrm{~Pa}$ and $10 \mathrm{~Pa}$ in the experiment, see fig. 13 (a). The used error bars result from the measurement of the neutral molecular density $\mathrm{O}_{2}\left(\mathrm{X}^{3} \Sigma_{\mathrm{g}}^{-}\right)$by VUV absorption. Nevertheless, the calculated total pressure follows the total pressure 5 and $10 \mathrm{~Pa}$ in the experiment without significant deviations during the E-H transition. In the case of $5 \mathrm{~Pa}$ the calculation with $\gamma_{\mathrm{O} 2(\mathrm{~b})}=0.1$ and reduced oxygen dissociation rates, respectively, reveals slightly decreasing total pressure in the $\mathrm{H}$ mode.

The calculated dissociation degree for 5 and $10 \mathrm{~Pa}$ increases during the E-H mode transition over two orders of magnitude, see fig. 13 (b). The relative low dissociation degree results from the large buffer volume $V_{\mathrm{R}}$ compared with small plasma volume $V_{\mathrm{P}}$.

For the calculated density of $\mathrm{O}\left({ }^{3} \mathrm{P}\right), \mathrm{O}_{2}\left(\mathrm{~b}^{1} \Sigma_{\mathrm{g}}^{+}\right)$and $\mathrm{O}^{-}$the normalized source and loss rates are evaluated for total pressure of $5 \mathrm{~Pa}$ during the E-H mode transition concerning their impact on the considered rate equation, see figs.14, 15, and 16, respectively. Here, the normalized rates are involved at level larger than about $10^{-4}$.

The normalized source rates for $\mathrm{O}\left({ }^{3} \mathrm{P}\right)$ are plotted in fig.14 (a). Some of the normalized source rates $\left(R_{1}, R_{2}, R_{6}, R_{9}, R_{10}, R_{76}\right.$, $R_{77}, R_{78}$ ) show approximately the same qualitative behavior, which means no significant changes can be observed during E$\mathrm{H}$ mode transition. The normalized source rates $R_{15}$ and $R_{19}$ in-

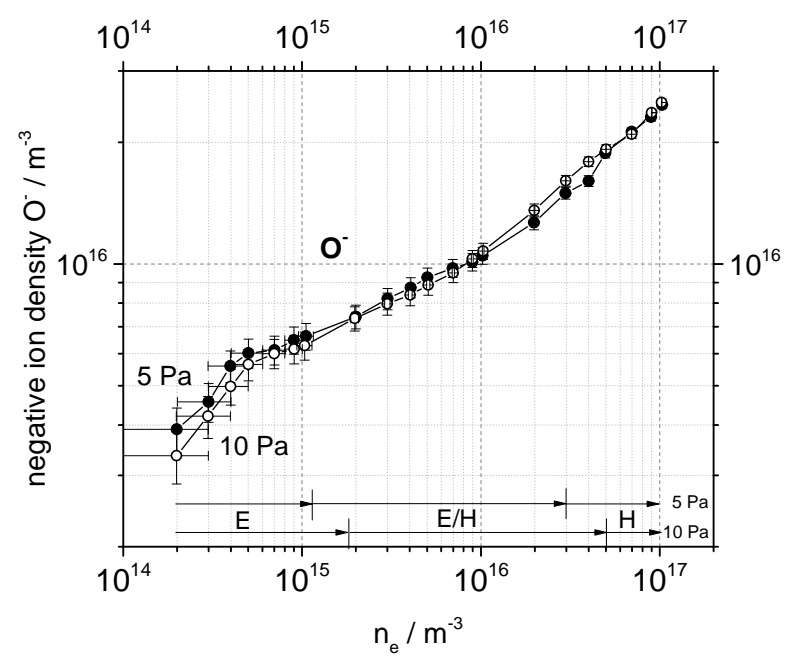

Fig. 7. Averaged $\mathrm{O}^{-}$density determined from laser photodetachment experiment and the collision detachment in early afterglow vs. electron density during E-H transition at $5 \mathrm{~Pa}$ and $10 \mathrm{~Pa}$. Data are taken from [33].

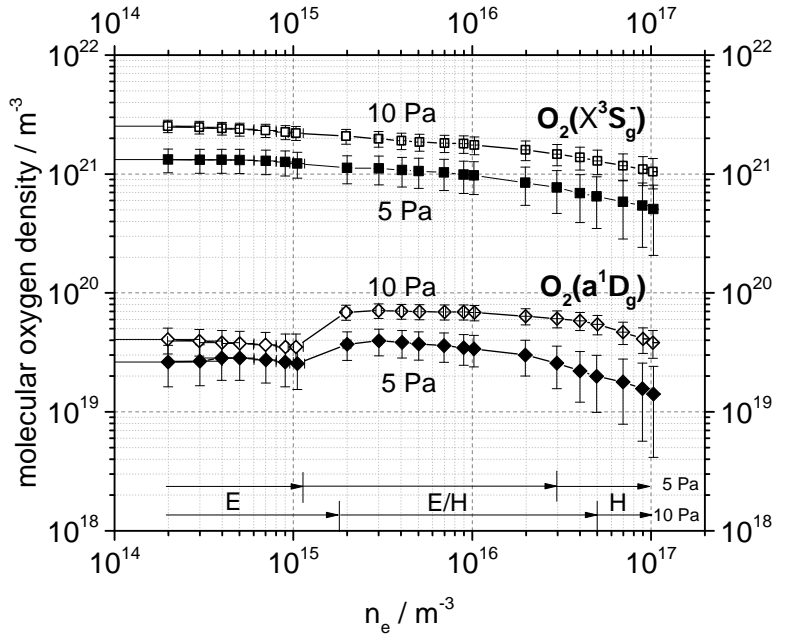

Fig. 8. Averaged density of molecular ground state $\mathrm{O}_{2}\left(\mathrm{X}^{3} \Sigma_{\mathrm{g}}^{-}\right)$and singlet metastable state $\mathrm{O}_{2}\left(\mathrm{a}^{1} \Delta_{\mathrm{g}}\right)$ vs. electron density during E-H transition from VUV absorption at $5 \mathrm{~Pa}$ and $10 \mathrm{~Pa}$. Data are taken from [27].

crease about two orders of magnitude due to increasing $\mathrm{O}_{2}\left(\mathrm{~b}^{1} \Sigma_{\mathrm{g}}^{+}\right)$ density, and $R_{4}$ decreases by more than one order of magnitude due to decreasing electron temperature, respectively. The most important source of $\mathrm{O}\left({ }^{3} \mathrm{P}\right)$ is the electron impact dissociation of ground state molecular oxygen $\mathrm{O}_{2}\left(\mathrm{X}^{3} \Sigma_{\mathrm{g}}^{-}\right)$with normalized rates $R_{2}$ and $R_{1}$ at the level of about $4 \times 10^{-1}$ and $1.5 \times 10^{-1}$, respectively, and the reaction between $\mathrm{O}_{2}\left(\mathrm{X}^{3} \Sigma_{\mathrm{g}}^{-}\right)$and $\mathrm{O}\left({ }^{1} \mathrm{D}\right)$ with normalized rate $R_{78}$ at the level of about $3 \times 10^{-1}$. Furthermore, the normalized rate $R_{10}$, involving electron impact dissociation of $\mathrm{O}_{2}\left(\mathrm{a}^{1} \Delta_{\mathrm{g}}\right)$, amounts to about $1.5 \times 10^{-2}$. The dominating loss rate for $\mathrm{O}\left({ }^{3} \mathrm{P}\right)$ is the wall loss at the internal stainless steel surface of the vacuum chamber, $R_{\text {wall }}$ amounts to between $9.99 \times 10^{-1}$ and $9.98 \times 10^{-1}$. At lower level the normalized loss rate $R_{21}$, assigned to the electron impact excitation of $\mathrm{O}\left({ }^{3} \mathrm{P}\right)$ into $\mathrm{O}\left({ }^{1} \mathrm{D}\right)$, raises continuously over 2 orders of magnitude during E-H mode transition on the level of about $2.5 \times 10^{-3}$.

The source for the metastable molecule $\mathrm{O}_{2}\left(\mathrm{~b}^{1} \Sigma_{\mathrm{g}}^{+}\right)$includes the reactions $R_{7}, R_{13}$ and $R_{78}$, see fig.15 (a). The normalized source rate $R_{78}$, assigned to the reaction between $\mathrm{O}_{2}\left(\mathrm{X}^{3} \Sigma_{\mathrm{g}}^{-}\right)$and $\mathrm{O}\left({ }^{1} \mathrm{D}\right)$, is on the level between $9.7 \times 10^{-1}$ and $9.5 \times 10^{-3}$ during the E-H mode transition and represents the key reaction to produce $\mathrm{O}_{2}\left(\mathrm{~b}^{1} \Sigma_{\mathrm{g}}^{+}\right)$. The electron impact excitation of the ground state molecule $\mathrm{O}_{2}\left(\mathrm{X}^{3} \Sigma_{\mathrm{g}}^{-}\right)$contributes with normalized source rate $R_{7}$ between $2 \times 10^{-2}$ and $4 \times 10^{-2}$, whereas the normalized rate $R_{13}$, assigned to the electron impact excitation of the metastable molecule $\mathrm{O}_{2}\left(\mathrm{a}^{1} \Delta_{\mathrm{g}}\right)$, ranges between $4.8 \times 10^{-4}$ and $1.5 \times 10^{-3}$ during the E-H mode transition. Comparing the normalized loss rates of $\mathrm{O}_{2}\left(\mathrm{~b}^{1} \Sigma_{\mathrm{g}}^{+}\right)$in fig. 15 (b) the important loss reaction is the quenching at the reactor wall which changes with a normalized rate between $9.9 \times 10^{-1}$ and $1.5 \times 10^{-1}$ during the E-H mode transition. Following, the normalized loss rate $R_{19}$, assigned to the electron impact dissociation of $\mathrm{O}_{2}\left(\mathrm{~b}^{1} \Sigma_{\mathrm{g}}^{+}\right)$, contributes with the level between $2.3 \times 10^{-3}$ and $2.6 \times 10^{-1}$. 

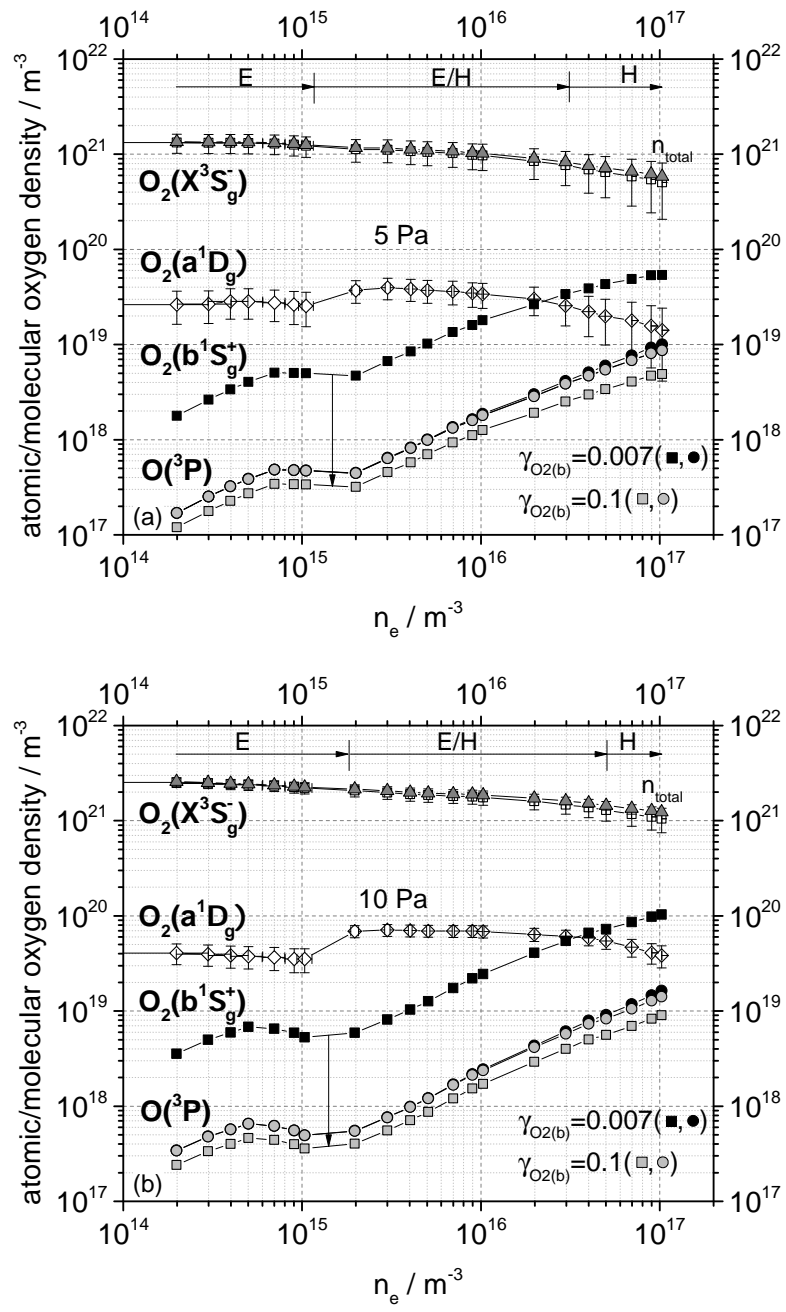

Fig. 9. Calculated (full symbols) and measured averaged density of neutral oxygen species as well as total number density vs. electron density during E-H transition at $5 \mathrm{~Pa}$ (a) and $10 \mathrm{~Pa}$ (b).

The other normalized loss rates $R_{14}, R_{15}, R_{17}, R_{44}, R_{71}$ and $R_{72}$ are below the level $5 \times 10^{-1}$.

Finally, the normalized rates are discussed for the source and loss of the negative atomic oxygen ions, see fig.16. As expected, the dissociative electron attachment with molecular ground state $\mathrm{O}_{2}\left(\mathrm{X}^{3} \Sigma_{\mathrm{g}}^{-}\right)$at the normalized rate $R_{6}$ is the dominant source for the $\mathrm{O}^{-}$, ranging between $6 \times 10^{-1}$ and $5 \times$ $10^{-1}$ during the E-H mode transition. The dissociative electron attachment with the molecular metastables contributes for $\mathrm{O}_{2}\left(\mathrm{a}^{1} \Delta_{\mathrm{g}}\right)$ by the normalized rates $R_{11}$ and $R_{12}$ on the level of about $10^{-2}$, and for $\mathrm{O}_{2}\left(\mathrm{~b}^{1} \Sigma_{\mathrm{g}}^{+}\right)$by the normalized rate $R_{16}$ on the level of between $4 \times 10^{-3}$ and $4 \times 10^{-1}$, respectively. The ion-ion pair production with the normalized rate $R_{5}$ decreases during the E-H mode transition from $3 \times 10^{-1}$ to $10^{-2}$ due to decreasing electron temperature. In fig. 16 (b) the dominant loss rates for $\mathrm{O}^{-}$are given by the collision detachment with the metastable oxygen molecules $\mathrm{O}_{2}\left(b^{1} \Sigma_{\mathrm{g}}^{+}\right)$in $R_{44}$ ranging between $2 \times 10^{-1}$ and $8 \times 10^{-1}$ as well as $\mathrm{O}_{2}\left(\mathrm{a}^{1} \Delta_{\mathrm{g}}\right)$ in $R_{42}$ at the level between $5 \times 10^{-2}$ and $2 \times 10^{-3}$ and from $2 \times 10^{-1}$
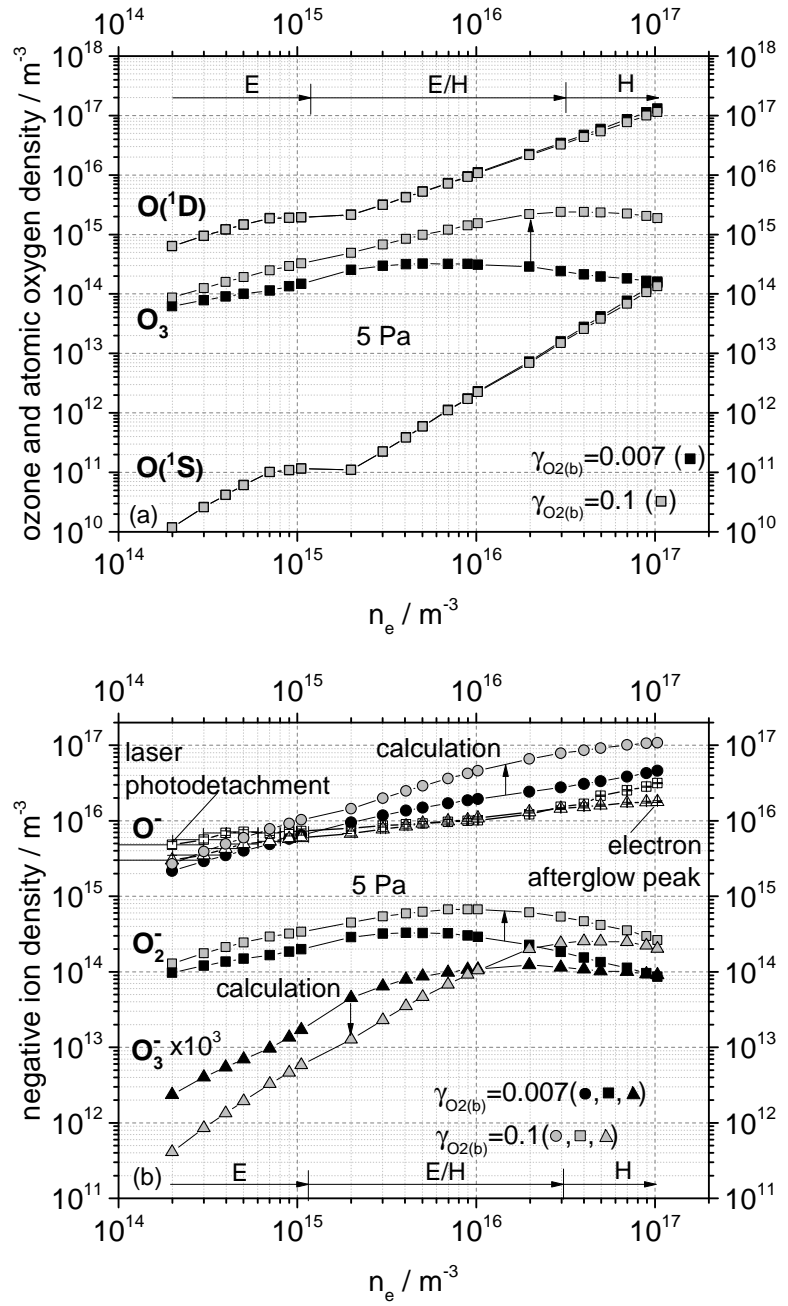

Fig. 10. Calculated density of $\mathrm{O}\left({ }^{1} \mathrm{D}\right), \mathrm{O}\left({ }^{1} \mathrm{~S}\right)$ and $\mathrm{O}_{3}$ (a) and density of $\mathrm{O}^{-}, \mathrm{O}_{2}^{-}$and $\mathrm{O}_{3}^{-}$(b) vs. electron density during E-H transition at $5 \mathrm{~Pa}$.

to $1 \times 10^{-2}$ for $R_{43}$, respectively. The normalized loss rate $R_{39}$ describes the $\mathrm{O}^{-}$loss in collision with $\mathrm{O}_{2}\left(\mathrm{X}^{3} \Sigma_{\mathrm{g}}^{-}\right)$at the level from $5 \times 10^{-1}$ to $2 \times 10^{-2}$ during the $\mathrm{E}-\mathrm{H}$ mode transition. The normalized loss rate $R_{30}$, assigned to the detachment of $\mathrm{O}^{-}$by electrons, increases from $2 \times 10^{-3}$ to $5 \times 10^{-2}$. The ion-ion recombination between $\mathrm{O}^{-}$and $\mathrm{O}_{2}^{+}$with normalized loss rates $R_{59}$ and $R_{60}$ ranges between $7 \times 10^{-3}$ and $3 \times 10^{-2}$, while loss rate $R_{57}$ for ion-ion recombination between $\mathrm{O}^{-}$and $\mathrm{O}^{+}$shows similar behavior at lower level between $2 \times 10^{-3}$ and $7 \times 10^{-3}$ during E-H mode transition.

\section{Summary and conclusions}

Analytical rate equation calculations of volume averaged global model are performed for oxygen ICP during the E-H mode transition taking into calculation experimental results as input data. The used experimental setup is briefly described including the radio frequency $(13.56 \mathrm{MHz}) \mathrm{ICP}$ at low pressure and the comprehensive diagnostics, [27],[33]. The results are presented for the electron and gas temperature as well as the 
density of electrons, neutral ground and metastable molecules $\mathrm{O}_{2}\left(\mathrm{X}^{3} \Sigma_{\mathrm{g}}^{-}\right)$and $\mathrm{O}_{2}\left(\mathrm{a}^{1} \Delta_{\mathrm{g}}\right)$ as well as the negative atomic oxygen $\mathrm{O}^{-}$. The electron/gas temperature and the density of electrons, $\mathrm{O}_{2}\left(\mathrm{X}^{3} \Sigma_{\mathrm{g}}^{-}\right)$and $\mathrm{O}_{2}\left(\mathrm{a}^{1} \Delta_{\mathrm{g}}\right)$ are used as input data in the rate equation calculations to determine the averaged density of $\mathrm{O}\left({ }^{3} \mathrm{P}\right), \mathrm{O}_{2}\left(\mathrm{~b}^{1} \Sigma_{\mathrm{g}}^{+}\right), \mathrm{O}\left({ }^{1} \mathrm{D}\right), \mathrm{O}\left({ }^{1} \mathrm{~S}\right), \mathrm{O}_{3}, \mathrm{O}^{-}, \mathrm{O}_{2}^{-}$, and $\mathrm{O}_{3}^{-}$. The global model is adequate because the used densities from the experiment are averaged densities from line-integrated methods (Gaussian beam microwave interferometry and VUV absorption spectroscopy). Due to the specific experimental set up and the used plasma processing parameters, a plasma chemical back-mixing reactor for the neutrals is taken into consideration. The necessary rate coefficients for the rate equation system are taken from the corresponding literature. The rate equation system was solved by self-consistent calculations using iteration procedure with equalized balance for the total source and loss rate as control parameter for each species. An important point is the knowledge of the sticking coefficient for neutral species at the internal stainless steel surface of the vacuum chamber. For $\mathrm{O}_{2}\left(\mathrm{~b}^{1} \Sigma_{\mathrm{g}}^{+}\right)$we used a sticking coefficient $\gamma_{\mathrm{O} 2(\mathrm{~b})}=0.007$ in comparison with $\gamma_{\mathrm{O} 2(\mathrm{~b})}=0.1$. The higher sticking coefficient results in reduced $\mathrm{O}_{2}\left(\mathrm{~b}^{1} \Sigma_{\mathrm{g}}^{+}\right)$density by about one order of magnitude whereas the $\mathrm{O}^{-}$density increases a half order of magnitude in the $\mathrm{E}-\mathrm{H} / \mathrm{H}$ mode. No significant changes are found for $\mathrm{O}\left({ }^{3} \mathrm{P}\right), \mathrm{O}\left({ }^{1} \mathrm{D}\right)$ and $\mathrm{O}\left({ }^{1} \mathrm{~S}\right)$ whereas $\mathrm{O}_{3}$ increases by one order of magnitude in the $\mathrm{E}-\mathrm{H} / \mathrm{H}$ mode. Furthermore, the results are compared between our rate equation calculations using rate coefficients for oxygen dissociation from Gudmundsson [46] and that from Gudmundsson and Thorsteinsson [43], respectively. The usage of the rate coefficients for oxygen dissociation from [43] results in reduction of the calculated neutral species $\mathrm{O}\left({ }^{3} \mathrm{P}\right), \mathrm{O}_{2}\left(\mathrm{~b}^{1} \Sigma_{\mathrm{g}}^{+}\right), \mathrm{O}\left({ }^{1} \mathrm{D}\right), \mathrm{O}\left({ }^{1} \mathrm{~S}\right)$ by about one order of magnitude, whereas the ozone density increases in the $\mathrm{E}-\mathrm{H} / \mathrm{H}$ mode by about one order of magnitude. The $\mathrm{O}^{-}$density increases on the same level as the calculation with increased sticking coefficient of $\gamma_{\mathrm{O} 2(\mathrm{~b})}$. The best agreement between measured and calculated $\mathrm{O}^{-}$density was found with the rate coefficients in tabl.1

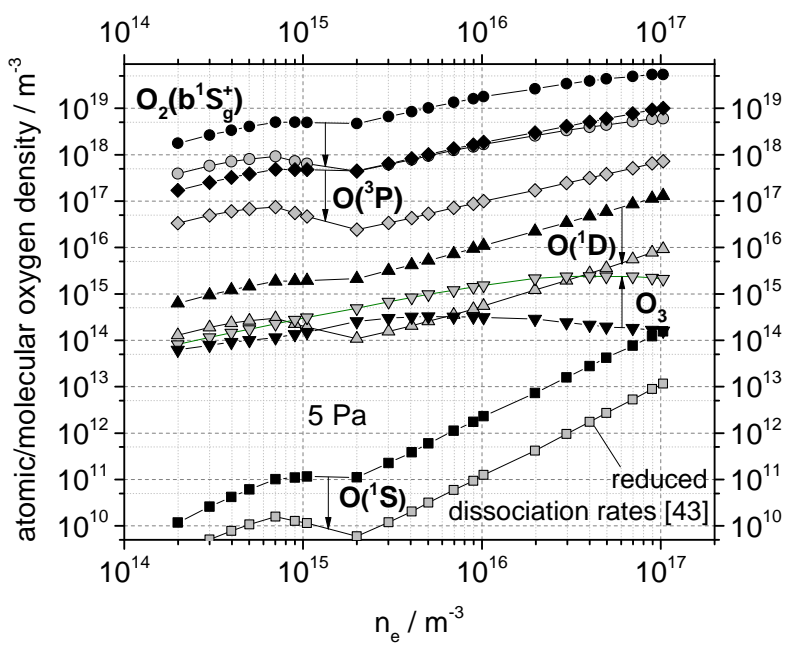

Fig. 11. Calculated density of neutral oxygen species vs. electron density during $\mathrm{E}-\mathrm{H}$ transition at $5 \mathrm{~Pa}$ in comparison with the used rate coefficients for oxygen dissociation in [43].
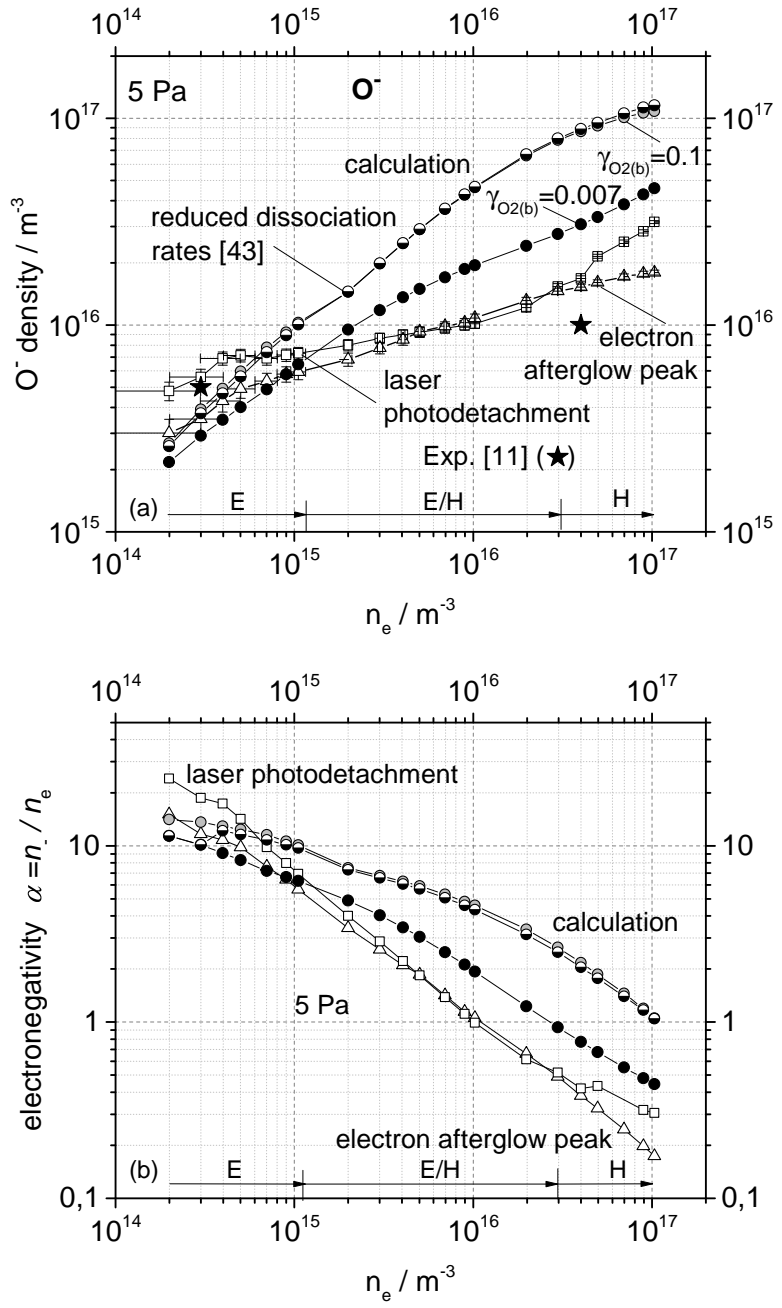

Fig. 12. Calculated $\mathrm{O}^{-}$density with variation of the $\mathrm{O}_{2}\left(\mathrm{~b}^{1} \Sigma_{\mathrm{g}}^{+}\right)$sticking coefficient and the rate coefficients for oxygen dissociation [43] in comparison with the measured negative ion density including 2 data points from [11] (a) and the corresponding electronegativity (b) during the E-H transition at $5 \mathrm{~Pa}$.

and $\gamma_{\mathrm{O} 2(\mathrm{~b})}=0.007$ with deviation by a factor of 2 . Finally, the normalized source and loss rates for $\mathrm{O}\left({ }^{3} \mathrm{P}\right), \mathrm{O}_{2}\left(\mathrm{~b}^{1} \Sigma_{\mathrm{g}}^{+}\right)$and $\mathrm{O}^{-}$are evaluated concerning their contribution in the rate equation calculations. Despite some uncertainties and lack of certified data the used global model with implementation of experimental data provides interesting information about the density of relevant oxygen species in $13.56 \mathrm{MHz}$ ICP during the E-H mode transition. 

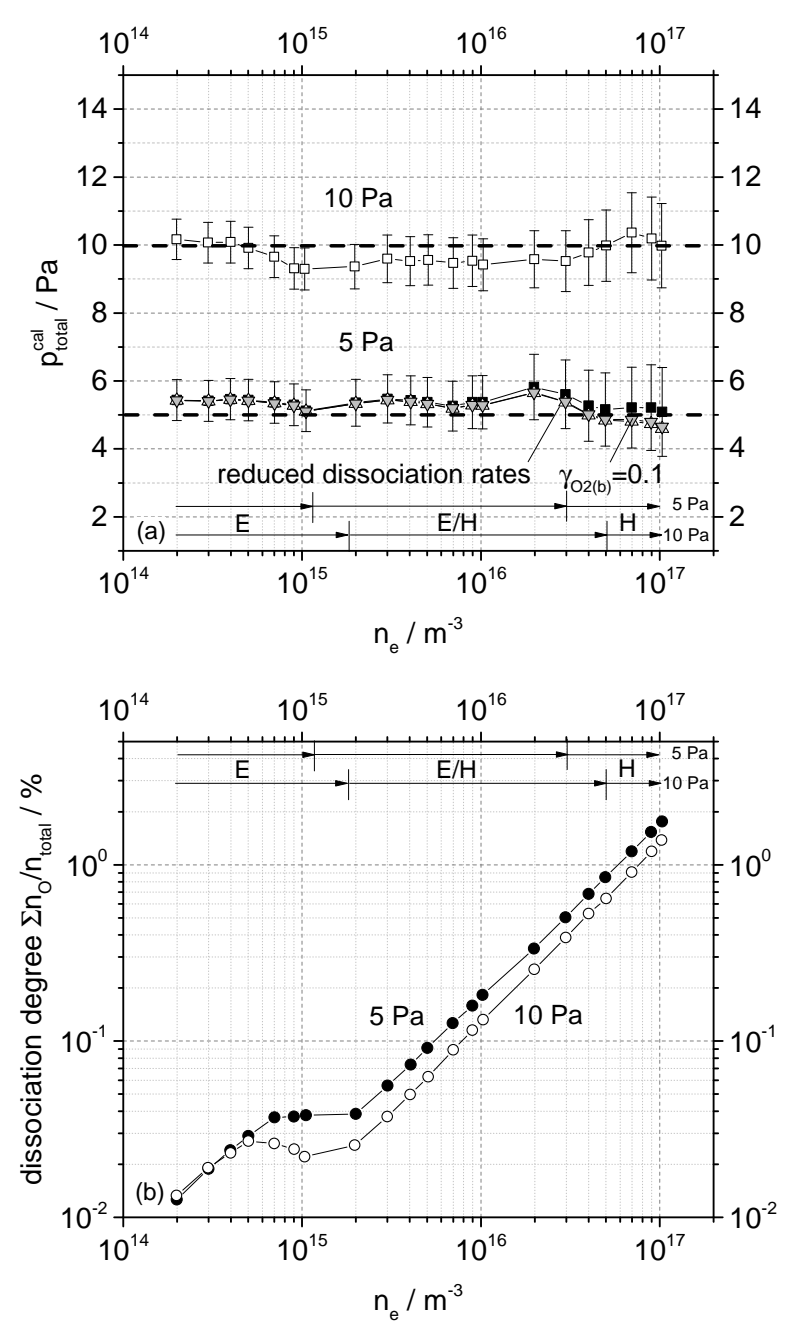

Fig. 13. Total pressure from calculated and measured oxygen species (experiment $5 \mathrm{~Pa}, 10 \mathrm{~Pa}$ ) including the variation of the $\mathrm{O}_{2}\left(\mathrm{~b}^{1} \Sigma_{\mathrm{g}}^{+}\right)$sticking coefficient and the rate coefficients for oxygen dissociation in [43] for $5 \mathrm{~Pa}$ (a) and the calculated dissociation degree for atomic oxygen (b).

\section{Acknowledgement}

This work was supported by the Deutsche Forschungsgemeinschaft within the framework of the Collaborative Research Center (CRC) Transregio 24 "Fundamentals of Complex Plasmas". We would like to thank Kristian Dittmann and Christian Küllig for their significant contributions in the investigation of RF plasmas, particularly in the first and second funding period in project B5 of the CRC Transregio 24.

\section{Author contribution statement}

J Meichsner has written the paper, implemented the volume averaged global model, performed the rate equation calculation, and generated the figures with the experimental and calculated data. Th Wegner has performed the experiments, generated the experimental data and edited the paper including discussion.
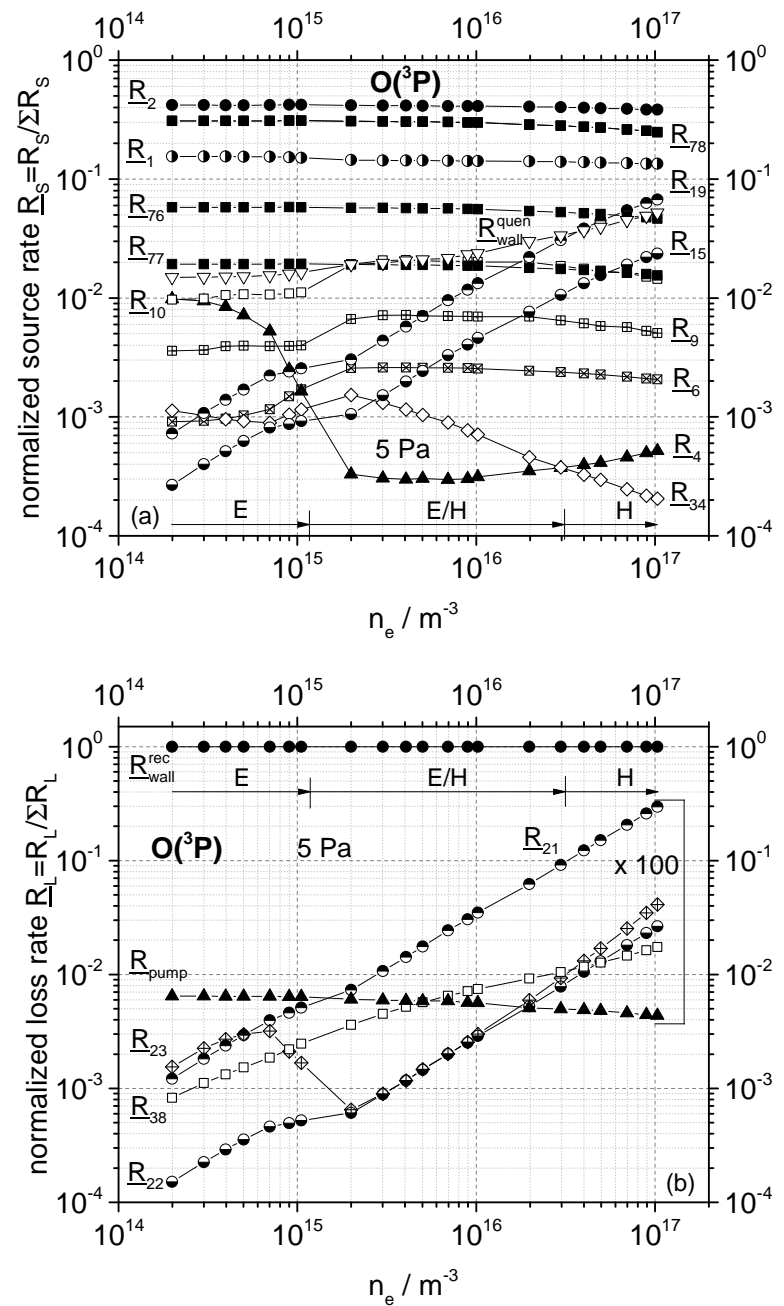

Fig. 14. Normalized source rates (a) and loss rates (b) for $\mathrm{O}\left({ }^{3} \mathrm{P}\right)$ vs. electron density at $5 \mathrm{~Pa}$.

\section{References}

1. P.C. Boyle, A.R. Ellingboe, M.M. Turner, Plasma Sources Science and Technology 13, 493 (2004)

2. T. Kitajima, Y. Takeo, Z.L. Petrović, T. Makabe, Applied Physics Letters 77, 489 (2000)

3. T. Denda, Y. Miyoshi, Y. Komukai, T. Goto, Z.L. Petrović, T. Makabe, Journal of Applied Physics 95, 870 (2004)

4. J.K. Lee, O.V. Manuilenko, N.Y. Babaeva, H.C. Kim, J.W. Shon, Plasma Sources Science and Technology 14, 89 (2005)

5. A.R. Gibson, T. Gans, Plasma Sources Science and Technology 26, 115007 (2017)

6. B.G. Heil, R.P. Brinkmann, U. Czarnetzki, Journal of Physics D: Applied Physics 41, 225208 (2008)

7. Z. Donkó, J. Schulze, B.G. Heil, U. Czarnetzki, Journal of Physics D: Applied Physics 42, 025205 (2009)

8. J. Schulze, E. Schüngel, Z. Donkó, U. Czarnetzki, Plasma Sources Science and Technology 20, 015017 (2011)

9. J. Schulze, A. Derzsi, K. Dittmann, T. Hemke, J. Meichsner, Z. Donkó, Phys. Rev. Lett. 107, 275001 (2011)

10. J.T. Gudmundsson, I.G. Kouznetsov, K.K. Patel, M.A. Lieberman, Journal of Physics D: Applied Physics 34, 1100 (2001) 

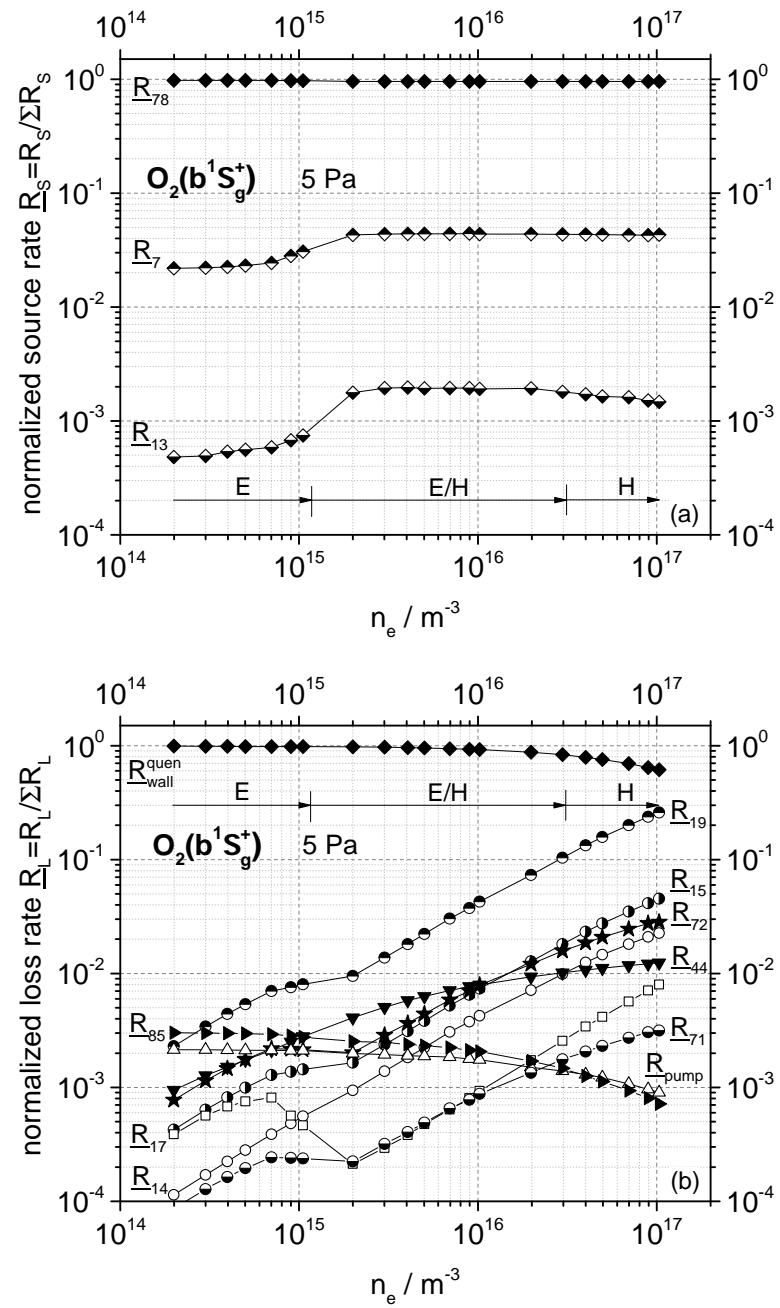

Fig. 15. Normalized source rates (a) and loss rates (b) for $\mathrm{O}_{2}\left(\mathrm{~b}^{1} \Sigma_{\mathrm{g}}^{+}\right)$ vs. electron density at $5 \mathrm{~Pa}$.

11. C.S. Corr, S. Gomez, W.G. Graham, Plasma Sources Science and Technology 21, 055024 (2012)

12. E. Despiau-Pujo, P. Chabert, Plasma Sources Science and Technology 18, 045028 (2009)

13. C. Küllig, K. Dittmann, Th. Wegner, I. Sheykin, K. Matyash, D. Loffhagen, R. Schneider, J. Meichsner, Contributions to Plasma Physics 52, 836 (2012)

14. A. Greb, K. Niemi, D. O'Connell, G.J. Ennis, N. MacGearailt, T. Gans, Physics of Plasmas 20, 053502 (2013)

15. D.A. Toneli, R.S. Pessoa, M. Roberto, J.T. Gudmundsson, Journal of Physics D: Applied Physics 48, 325202 (2015)

16. Y.X. Liu, I. Korolov, E. Schüngel, Y.N. Wang, Z. Donkó, J. Schulze, Plasma Sources Science and Technology 26, 055024 (2017)

17. K. Dittmann, K. Matyash, S. Nemschokmichal, J. Meichsner R. Schneider, Contributions to Plasma Physics 50, 942 (2010)

18. K. Matyash, R. Schneider, F. Taccogna, A. Hatayama, S. Longo, M. Capitelli, D. Tskhakaya, F.X. Bronold, Contributions to Plasma Physics 47, 595 (2007)

19. T. Teichmann, C. Küllig, K. Dittmann, K. Matyash, R. Schneider, J. Meichsner, Physics of Plasmas 20, 113509 (2013)
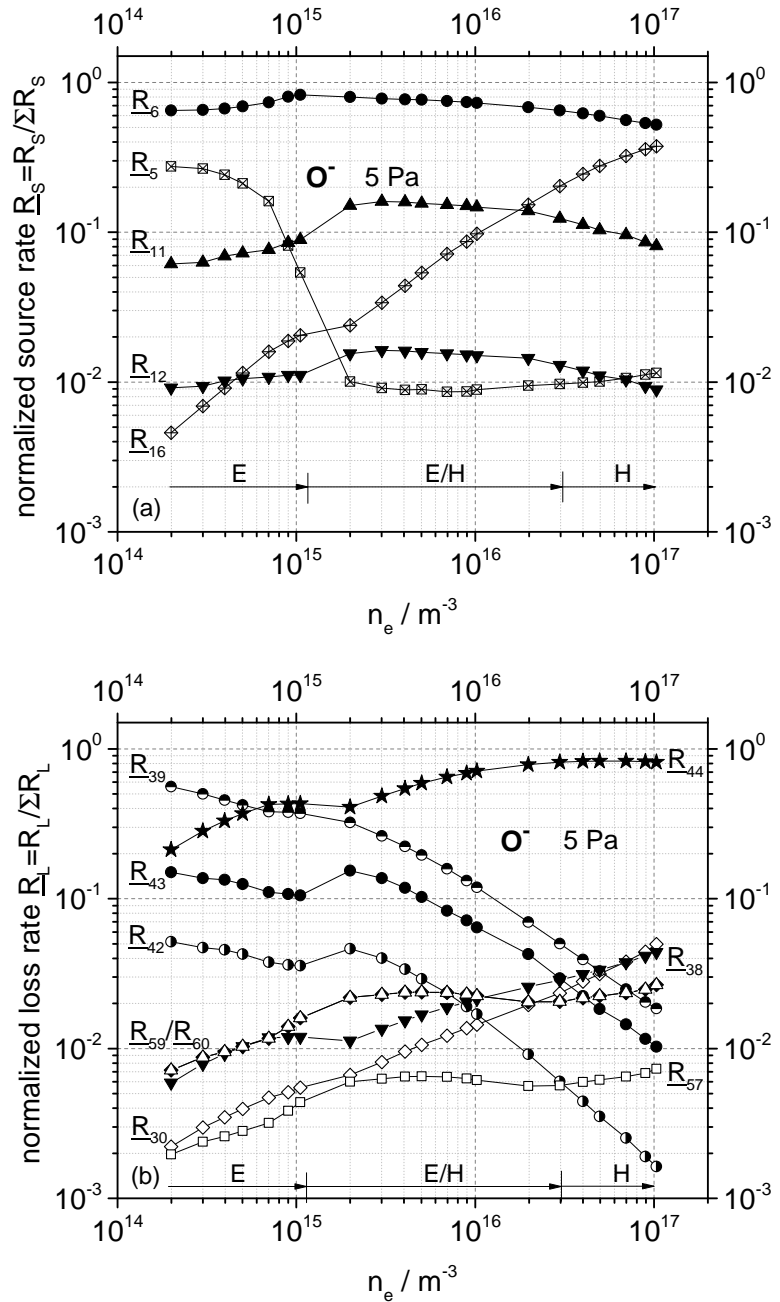

Fig. 16. Normalized source rates (a) and loss rates (b) for $\mathrm{O}^{-}$vs. electron density at $5 \mathrm{~Pa}$.

20. Y.H. Im, J.S. Park, C.S. Choi, R.J. Choi, Y.B. Hahn, S.H. Lee, J.K. Lee, Journal of Vacuum Science \& Technology A: Vacuum, Surfaces, and Films 19, 1315 (2001)

21. M.H. Shin, M.S. Park, N.E. Lee, J. Kim, C.Y. Kim, J. Ahn, Journal of Vacuum Science \& Technology A: Vacuum, Surfaces, and Films 24, 1373 (2006)

22. C.F. Carlström, R. van der Heijden, F. Karouta, R.W. van der Heijden, H.W.M. Salemink, E. van der Drift, Journal of Vacuum Science \& Technology B: Microelectronics and Nanometer Structures Processing, Measurement, and Phenomena 24, L6 (2006)

23. T. Ono, T. Akagi, T. Ichiki, Journal of Applied Physics 105 013314 (2009)

24. A. von Keudell, P. Awakowicz, J. Benedikt, V. Raballand, A. Yanguas-Gil, J. Opretzka, C. Flötgen, R. Reuter, L. Byelykh, H. Halfmann et al., Plasma Processes and Polymers 7, 327 (2010)

25. O. Kylián, B. Denis, K. Stapelmann, A. Ruiz, H. Rauscher, F. Rossi, Plasma Processes and Polymers 8, 1137 (2011)

26. K. Yoshino, H. Matsumoto, T. Iwasaki, S. Kinoshita, K. Noda, S. Iwamori, Vacuum 93, 84 (2013)

27. Th. Wegner, C. Küllig, J. Meichsner, Plasma Sources Science and Technology 26, 025006 (2017)

28. K. Dittmann, C. Küllig, J. Meichsner, Plasma Sources Science and Technology 21, 024001 (2012) 
29. Th. Wegner, C. Küllig, J. Meichsner, Contributions to Plasma Physics 55, 728 (2015)

30. C. Küllig, Th. Wegner, J. Meichsner, Plasma Sources Science and Technology 24, 015027 (2015)

31. Th. Wegner, C. Küllig, J. Meichsner, Plasma Sources Science and Technology 24, 044001 (2015)

32. C. Küllig, K. Dittmann, J. Meichsner, Plasma Sources Science and Technology 19, 065011 (2010)

33. Th. Wegner, C. Küllig, J. Meichsner, Plasma Sources Science and Technology 26, 025007 (2017)

34. C. Küllig, K. Dittmann, J. Meichsner, Physics of Plasmas 19, 073517 (2012)

35. C. Nowlan, C. McElroy, J. Drummond, Journal of Quantitative Spectroscopy and Radiative Transfer 108, 371 (2007)

36. M. Zaka-ul-Islam, K. Niemi, T. Gans, D. O'Connell, Applied Physics Letters 99, 041501 (2011)

37. J. Meichsner, M. Zeuner, B. Krames, M. Nitschke, R. Rochotzki, K. Barucki, Surface and Coatings Technology 98, 1565 (1998), papers presented at the Fifth International Conference on Plasma Surface Engineering

38. P.J. Chantry, Journal of Applied Physics 62, 1141 (1987)

39. H. Singh, D.B. Graves, Journal of Applied Physics 88, 3889 (2000)

40. A. Granier, F. Nicolazo, C. Vallée, A. Goullet, G. Turban, B. Grolleau, Plasma Sources Science and Technology 6, 147 (1997)

41. J.P. Booth, O. Joubert, J. Pelletier, N. Sadeghi, Journal of Applied Physics 69, 618 (1991)

42. S. Gomez, P.G. Steen, W.G. Graham, Applied Physics Letters 81, 19 (2002)

43. J.T. Gudmundsson, E.G. Thorsteinsson, Plasma Sources Science and Technology 16, 399 (2007)

44. H. Hannesdottir, J.T. Gudmundsson, Plasma Sources Science and Technology 25, 055002 (2016)

45. D.S. Stafford, M.J. Kushner, Journal of Applied Physics 96, 2451 (2004)

46. J.T. Gudmundsson, Tech. rep., Science Institute, University of Iceland (2004)

47. D.X. Liu, P. Bruggeman, F. Iza, M.Z. Rong, M.G. Kong, Plasma Sources Science and Technology 19, 025018 (2010)

48. D.X. Liu, M.Z. Rong, X.H. Wang, F. Iza, M.G. Kong, P. Bruggeman, Plasma Processes and Polymers 7, 846 (2010)

49. B. Eliasson, U. Kogelschatz, Basic data for modelling of electrical discharges in gases: oxygen (Brown Boveri Forschungszentrum CH-5405 Baden, 1986)

50. S. Pancheshnyi, Journal of Physics D: Applied Physics 46, 155201 (2013)

51. D.L. Baulch, R.A. Cox, P.J. Crutzen, R.F.H. Jr., J.A. Kerr, J. Troe, R.T. Watson, Journal of Physical and Chemical Reference Data 11, 327 (1982) 


\begin{tabular}{|c|c|c|c|}
\hline$\#$ & Reaction & Rate coefficient in $\mathrm{m}^{3} / \mathrm{s}$ & Ref. \\
\hline & electron-oxygen collisions & & \\
\hline 1 & $\mathrm{e}^{-}+\mathrm{O}_{2} \rightarrow 2 \mathrm{O}+\mathrm{e}^{-}$ & $6.86 \times 10^{-15} \exp \left(-6.29 / T_{\mathrm{e}}\right)$ & [46] \\
\hline 2 & $\mathrm{e}^{-}+\mathrm{O}_{2} \rightarrow \mathrm{O}\left({ }^{1} \mathrm{D}\right)+\mathrm{O}+\mathrm{e}^{-}$ & $3.49 \times 10^{-14} \exp \left(-5.92 / T_{\mathrm{e}}\right)$ & [46] \\
\hline 3 & $\mathrm{e}^{-}+\mathrm{O}_{2} \rightarrow \mathrm{O}\left({ }^{1} \mathrm{D}\right)+\mathrm{O}\left({ }^{1} \mathrm{D}\right)+\mathrm{e}^{-}$ & $1.44 \times 10^{-16} \exp \left(-17.25 / T_{\mathrm{e}}\right)$ & [46] \\
\hline 4 & $\mathrm{e}^{-}+\mathrm{O}_{2} \rightarrow \mathrm{O}^{+}+\mathrm{O}+2 \mathrm{e}^{-}$ & $1.88 \times 10^{-16} T_{\mathrm{e}}^{1.699} \exp \left(-16.81 / T_{\mathrm{e}}\right)$ & [46] \\
\hline 5 & $\mathrm{e}^{-}+\mathrm{O}_{2} \rightarrow \mathrm{O}^{+}+\mathrm{O}^{-}+\mathrm{e}^{-}$ & $7.10 \times 10^{-17} T_{\mathrm{e}}^{0.5} \exp \left(-17 / T_{\mathrm{e}}\right)$ & [46] \\
\hline 6 & $\mathrm{e}^{-}+\mathrm{O}_{2} \rightarrow \mathrm{O}^{-}+\mathrm{O}$ & $1.07 \times 10^{-15} T_{\mathrm{e}}^{-1.391} \exp \left(-6.26 / T_{\mathrm{e}}\right)$ & [46] \\
\hline 7 & $\mathrm{e}^{-}+\mathrm{O}_{2} \rightarrow \mathrm{O}_{2}(\mathrm{~b})+\mathrm{e}^{-}$ & $3.24 \times 10^{-16} \exp \left(-2.218 / T_{\mathrm{e}}\right)$ & [46] \\
\hline 8 & $\mathrm{e}^{-}+\mathrm{O}_{2}(\mathrm{a}) \rightarrow \mathrm{O}^{+}+\mathrm{O}+2 \mathrm{e}^{-}$ & $1.88 \times 10^{-16} T_{\mathrm{e}}^{1.699} \exp \left(-15.83 / T_{\mathrm{e}}\right)$ & [46] \\
\hline 9 & $\mathrm{e}^{-}+\mathrm{O}_{2}(\mathrm{a}) \rightarrow 2 \mathrm{O}+\mathrm{e}^{-}$ & $6.86 \times 10^{-15} \exp \left(-5.31 / T_{\mathrm{e}}\right)$ & [46] \\
\hline 10 & $\mathrm{e}^{-}+\mathrm{O}_{2}(\mathrm{a}) \rightarrow \mathrm{O}+\mathrm{O}\left({ }^{1} \mathrm{D}\right)+\mathrm{e}^{-}$ & $3.49 \times 10^{-14} \exp \left(-4.94 / T_{\mathrm{e}}\right)$ & [46] \\
\hline 11 & $\mathrm{e}^{-}+\mathrm{O}_{2}(\mathrm{a}) \rightarrow \mathrm{O}^{-}+\mathrm{O}$ & $4.19 \times 10^{-15} T_{\mathrm{e}}^{-1.376} \exp \left(-5.19 / T_{\mathrm{e}}\right)$ & [46] \\
\hline 12 & $\mathrm{e}^{-}+\mathrm{O}_{2}(\mathrm{a}) \rightarrow \mathrm{O}^{-}+\mathrm{O}\left({ }^{1} \mathrm{D}\right)$ & $9.93 \times 10^{-16} T_{\mathrm{e}}^{-1.437} \exp \left(-7.44 / T_{\mathrm{e}}\right)$ & [46] \\
\hline 13 & $\mathrm{e}^{-}+\mathrm{O}_{2}(\mathrm{a}) \rightarrow \mathrm{O}_{2}(\mathrm{~b})+\mathrm{e}^{-}$ & $3.24 \times 10^{-16} \exp \left(-1.57 / T_{\mathrm{e}}\right)$ & [47] \\
\hline 14 & $\mathrm{e}^{-}+\mathrm{O}_{2}(\mathrm{~b}) \rightarrow \mathrm{O}_{2}+\mathrm{e}^{-}$ & $9.72 \times 10^{-16} \exp \left(-0.591 / T_{\mathrm{e}}\right)$ & [46] \\
\hline 15 & $\mathrm{e}^{-}+\mathrm{O}_{2}(\mathrm{~b}) \rightarrow 2 \mathrm{O}+\mathrm{e}^{-}$ & $6.86 \times 10^{-15} \exp \left(-4.66 / T_{\mathrm{e}}\right)$ & [47] \\
\hline 16 & $\mathrm{e}^{-}+\mathrm{O}_{2}(\mathrm{~b}) \rightarrow \mathrm{O}^{-}+\mathrm{O}$ & $4.19 \times 10^{-15} T_{\mathrm{e}}^{-1.376} \exp \left(-4.54 / T_{\mathrm{e}}\right)$ & [46] \\
\hline 17 & $\mathrm{e}^{-}+\mathrm{O}_{2}(\mathrm{~b}) \rightarrow \mathrm{O}_{2}^{+}+2 \mathrm{e}^{-}$ & $2.34 \times 10^{-15} T_{\mathrm{e}}^{1.03} \exp \left(-10.7 / T_{\mathrm{e}}\right)$ & [46] \\
\hline 18 & $\mathrm{e}^{-}+\mathrm{O}_{2}(\mathrm{~b}) \rightarrow \mathrm{O}^{+}+\mathrm{O}+2 \mathrm{e}^{-}$ & $1.88 \times 10^{-16} T_{\mathrm{e}}^{1.7} \exp \left(-15.2 / T_{\mathrm{e}}\right)$ & [46] \\
\hline 19 & $\mathrm{e}^{-}+\mathrm{O}_{2}(\mathrm{~b}) \rightarrow \mathrm{O}\left({ }^{1} \mathrm{D}\right)+\mathrm{O}+\mathrm{e}^{-}$ & $3.49 \times 10^{-14} \exp \left(-4.29 / T_{\mathrm{e}}\right)$ & [46] \\
\hline 20 & $\mathrm{e}^{-}+\mathrm{O}_{2}(\mathrm{~b}) \rightarrow \mathrm{O}\left({ }^{1} \mathrm{~S}\right)+\mathrm{O}+\mathrm{e}^{-}$ & $f\left(T_{\mathrm{e}}\right)$ & [48] \\
\hline 21 & $\mathrm{e}^{-}+\mathrm{O} \rightarrow \mathrm{O}\left({ }^{1} \mathrm{D}\right)+\mathrm{e}^{-}$ & $4.54 \times 10^{-15} \exp \left(-2.36 / T_{\mathrm{e}}\right)$ & [46] \\
\hline 22 & $\mathrm{e}^{-}+\mathrm{O} \rightarrow \mathrm{O}\left({ }^{1} \mathrm{~S}\right)+\mathrm{e}^{-}$ & $7.86 \times 10^{-16} \exp \left(-4.489 / T_{\mathrm{e}}\right)$ & [46] \\
\hline 23 & $\mathrm{e}^{-}+\mathrm{O} \rightarrow \mathrm{O}^{+}+2 \mathrm{e}^{-}$ & $9.00 \times 10^{-15} T_{\mathrm{e}}^{0.7} \exp \left(-13.6 / T_{\mathrm{e}}\right)$ & [46] \\
\hline 24 & $\mathrm{e}^{-}+\mathrm{O}\left({ }^{1} \mathrm{D}\right) \rightarrow \mathrm{O}+\mathrm{e}^{-}$ & $8.17 \times 10^{-15} \exp \left(-0.4 / T_{\mathrm{e}}\right)$ & [46] \\
\hline 25 & $\mathrm{e}^{-}+\mathrm{O}\left({ }^{1} \mathrm{D}\right) \rightarrow \mathrm{O}^{+}+2 \mathrm{e}^{-}$ & $9.00 \times 10^{-15} T_{\mathrm{e}}^{0.7} \exp \left(-11.6 / T_{\mathrm{e}}\right)$ & [46] \\
\hline 26 & $\mathrm{e}^{-}+\mathrm{O}\left({ }^{1} \mathrm{~S}\right) \rightarrow \mathrm{O}^{+}+2 \mathrm{e}^{-}$ & $6.60 \times 10^{-15} T_{\mathrm{e}}^{0.6} \exp \left(-9.43 / T_{\mathrm{e}}\right)$ & [47] \\
\hline 27 & $\mathrm{e}^{-}+\mathrm{O}^{+} \rightarrow \mathrm{O}\left({ }^{1} \mathrm{D}\right)$ & $5.30 \times 10^{-19} T_{\mathrm{e}}^{-0.5}$ & [47] \\
\hline 28 & $\mathrm{e}^{-}+\mathrm{O}_{2}^{+} \rightarrow \mathrm{O}+\mathrm{O}\left({ }^{1} \mathrm{D}\right)$ & $2.20 \times 10^{-14} T_{\mathrm{e}}^{-0.5}$ & [46] \\
\hline 29 & $\mathrm{e}^{-}+\mathrm{O}_{2}^{+} \rightarrow 2 \mathrm{O}\left({ }^{1} \mathrm{D}\right)$ & $6.87 \times 10^{-15} T_{\mathrm{e}}^{-0.7}$ & [47] \\
\hline 30 & $\mathrm{e}^{-}+\mathrm{O}^{-} \rightarrow \mathrm{O}+2 \mathrm{e}^{-}$ & $5.47 \times 10^{-14} T_{\mathrm{e}}^{0.324} \exp \left(-2.98 / T_{\mathrm{e}}\right)$ & [46] \\
\hline 31 & $\mathrm{e}^{-}+\mathrm{O}_{3} \rightarrow \mathrm{O}+\mathrm{O}_{2}+\mathrm{e}^{-}$ & $5.88 \times 10^{-15}$ & [49] \\
\hline 32 & $\mathrm{e}^{-}+\mathrm{O}_{3} \rightarrow \mathrm{O}^{-}+\mathrm{O}_{2}$ & $2.12 \times 10^{-15} T_{\mathrm{e}}^{-1.058} \exp \left(-0.93 / T_{\mathrm{e}}\right)$ & [46] \\
\hline 33 & $\begin{array}{l}\mathrm{e}^{-}+\mathrm{O}_{3} \rightarrow \mathrm{O}+\mathrm{O}_{2}^{-} \\
\text {ion-neutral collisions }\end{array}$ & $9.76 \times 10^{-14} T_{\mathrm{e}}^{-1.309} \exp \left(-1.007 / T_{\mathrm{e}}\right)$ & [46] \\
\hline 34 & $\mathrm{O}^{+}+\mathrm{O}_{2} \rightarrow \mathrm{O}+\mathrm{O}_{2}^{+}$ & $2.00 \times 10^{-17}\left(300 / T_{\mathrm{gas}}\right)^{0.5}$ & [46] \\
\hline 35 & $\mathrm{O}^{+}+\mathrm{O}_{3}(a) \rightarrow \mathrm{O}+\mathrm{O}_{2}^{+}$ & $2.00 \times 10^{-17}$ & [15] \\
\hline 36 & $\mathrm{O}^{+}+\mathrm{O}_{3} \rightarrow \mathrm{O}_{2}^{+}+\mathrm{O}_{2}$ & $1.00 \times 10^{-16}$ & [46] \\
\hline 37 & $\mathrm{O}_{2}^{+}+\mathrm{O}\left({ }^{1} \mathrm{D}\right) \rightarrow \mathrm{O}_{2}(\mathrm{a})+\mathrm{O}^{+}$ & $1.00 \times 10^{-18}\left(300 / T_{\mathrm{gas}}\right)^{0.5}$ & [47] \\
\hline 38 & $\mathrm{O}^{-}+\mathrm{O} \rightarrow \mathrm{O}_{2}+\mathrm{e}^{-}$ & $2.00 \times 10^{-16}\left(T_{\mathrm{gas}} / 300\right)^{0.5}$ & [47] \\
\hline 39 & $\mathrm{O}^{-}+\mathrm{O}_{2}+\rightarrow \mathrm{O}+\mathrm{O}_{2}+\mathrm{e}^{-}$ & $2.40 \times 10^{-18}$ & [15] \\
\hline 40 & $\mathrm{O}^{-}+\mathrm{O}_{2}+\rightarrow \mathrm{O}_{2}^{-}+\mathrm{O}$ & $f\left(T_{\text {ion }}\right)$ & [50] \\
\hline 41 & $\mathrm{O}^{-}+\mathrm{O}_{2} \rightarrow \mathrm{O}_{3}+\mathrm{e}^{-}$ & $5.00 \times 10^{-21}\left(T_{\mathrm{gas}} / 300\right)^{0.5}$ & [48] \\
\hline 42 & $\mathrm{O}^{-}+\mathrm{O}_{2}(\mathrm{a}) \rightarrow \mathrm{O}+\mathrm{O}_{2}^{-}$ & $1.10 \times 10^{-17}\left(300 / T_{\mathrm{gas}}\right)^{0.5}$ & [47] \\
\hline 43 & $\mathrm{O}^{-}+\mathrm{O}_{2}(\mathrm{a}) \rightarrow \mathrm{O}_{3}+\mathrm{e}^{-}$ & $3.30 \times 10^{-17}\left(T_{\text {gas }} / 300\right)^{0.5}$ & [46] \\
\hline 44 & $\mathrm{O}^{-}+\mathrm{O}_{2}(\mathrm{~b}) \rightarrow \mathrm{O}+\mathrm{O}_{2}+\mathrm{e}^{-}$ & $6.90 \times 10^{-16}\left(T_{\mathrm{gas}} / 300\right)^{0.5}$ & [46] \\
\hline 45 & $\mathrm{O}^{-}+\mathrm{O}_{3} \rightarrow 2 \mathrm{O}_{2}+\mathrm{e}$ & $3.10 \times 10^{-16}\left(T_{\text {gas }} / 300\right)^{0.5}$ & [47] \\
\hline 46 & $\mathrm{O}^{-}+\mathrm{O}_{3} \rightarrow \mathrm{O}_{3}^{-}+\mathrm{O}$ & $5.30 \times 10^{-16}$ & [49] \\
\hline 47 & $\mathrm{O}^{-}+\mathrm{O}_{3} \rightarrow \mathrm{O}_{2}^{-}+\mathrm{O}_{2}$ & $1.02 \times 10^{-17}\left(T_{\mathrm{gas}} / 300\right)^{0.5}$ & [47] \\
\hline 48 & $\mathrm{O}_{2}^{-}+\mathrm{O} \rightarrow \mathrm{O}_{2}+\mathrm{O}^{-}$ & $1.50 \times 10^{-16}\left(T_{\mathrm{gas}} / 300\right)^{0.5}$ & [47] \\
\hline 49 & $\mathrm{O}_{2}^{-}+\mathrm{O} \rightarrow \mathrm{O}_{3}+\mathrm{e}^{-}$ & $1.50 \times 10^{-16}\left(T_{\text {gas }} / 300\right)^{0.5}$ & [47] \\
\hline 50 & $\mathrm{O}_{2}^{-}+\mathrm{O}_{2} \rightarrow 2 \mathrm{O}_{2}+\mathrm{e}^{-}$ & $2.70 \times 10^{-16} \exp \left(-5590 / T_{\mathrm{gas}}\right)$ & [47] \\
\hline 51 & $\mathrm{O}_{2}^{-}+\mathrm{O}_{2}(\mathrm{a}) \rightarrow 2 \mathrm{O}_{2}+\mathrm{e}^{-}$ & $2.00 \times 10^{-16}\left(T_{\text {gas }} / 300\right)^{0.5}$ & [45] \\
\hline 52 & $\mathrm{O}_{2}^{-}+\mathrm{O}_{2}(\mathrm{~b}) \rightarrow 2 \mathrm{O}_{2}+\mathrm{e}^{-}$ & $3.60 \times 10^{-16}$ & [47] \\
\hline 53 & $\mathrm{O}_{2}^{-}+\mathrm{O}_{3} \rightarrow \mathrm{O}_{2}+\mathrm{O}_{3}^{-}$ & $4.00 \times 10^{-16}$ & [49] \\
\hline 54 & $\mathrm{O}_{3}^{-}+\mathrm{O} \rightarrow \mathrm{O}_{2}^{-}+\mathrm{O}_{2}$ & $1.00 \times 10^{-16}$ & [46] \\
\hline 55 & $\mathrm{O}_{3}^{-}+\mathrm{O} \rightarrow 2 \mathrm{O}_{2}+\mathrm{e}$ & $3.00 \times 10^{-16}$ & [49] \\
\hline 56 & $\mathrm{O}_{3}^{-}+\mathrm{O}_{2} \rightarrow \mathrm{O}_{3}+\mathrm{O}_{2}$ & $2.30 \times 10^{-17}$ & [15] \\
\hline
\end{tabular}




\begin{tabular}{|c|c|c|c|}
\hline$\#$ & Reaction & Rate coefficient in $\mathrm{m}^{3} / \mathrm{s}$ & Ref. \\
\hline & ion-ion recombination & & \\
\hline 57 & $\mathrm{O}^{-}+\mathrm{O}^{+} \rightarrow 2 \mathrm{O}$ & $4.00 \times 10^{-14}\left(300 / T_{\text {ion }}\right)^{0.43}$ & {$[46]$} \\
\hline 58 & $\mathrm{O}^{-}+\mathrm{O}^{+} \rightarrow \mathrm{O}+\mathrm{O}\left({ }^{1} \mathrm{D}\right)$ & $4.90 \times 10^{-16}\left(300 / T_{\mathrm{gas}}\right)^{0.5}$ & {$[47]$} \\
\hline 59 & $\mathrm{O}^{-}+\mathrm{O}_{2}^{+} \rightarrow 3 \mathrm{O}$ & $2.60 \times 10^{-14}\left(300 / T_{\text {ion }}\right)^{0.44}$ & [46] \\
\hline 60 & $\mathrm{O}^{-}+\mathrm{O}_{2}^{+} \rightarrow \mathrm{O}+\mathrm{O}_{2}$ & $2.60 \times 10^{-14}\left(300 / T_{\text {ion }}\right)^{0.44}$ & {$[46]$} \\
\hline 61 & $\mathrm{O}_{2}^{-}+\mathrm{O}^{+} \rightarrow \mathrm{O}_{2}+\mathrm{O}$ & $2.70 \times 10^{-13}\left(300 / T_{\text {ion }}\right)^{0.5}$ & {$[46]$} \\
\hline 62 & $\mathrm{O}_{2}^{-}+\mathrm{O}_{2}^{+} \rightarrow 2 \mathrm{O}_{2}$ & $2.70 \times 10^{-13}\left(300 / T_{\text {ion }}\right)^{0.5}$ & {$[46]$} \\
\hline 63 & $\mathrm{O}_{2}^{-}+\mathrm{O}_{2}^{+} \rightarrow \mathrm{O}_{2}+2 \mathrm{O}$ & $1.01 \times 10^{-13}$ & [49] \\
\hline 64 & $\mathrm{O}_{3}^{-}+\mathrm{O}_{2}^{+} \rightarrow \mathrm{O}_{3}+\mathrm{O}_{2}$ & $2.00 \times 10^{-13}\left(300 / T_{\mathrm{gas}}\right)^{0.5}$ & {$[46]$} \\
\hline 65 & $\mathrm{O}_{3}^{-}+\mathrm{O}_{2}^{+} \rightarrow \mathrm{O}_{3}+2 \mathrm{O}$ & $1.01 \times 10^{-13}\left(300 / T_{\mathrm{gas}}\right)^{0.5}$ & [46] \\
\hline 66 & $\begin{array}{l}\mathrm{O}_{3}^{-}+\mathrm{O}^{+} \rightarrow \mathrm{O}_{3}+\mathrm{O} \\
\text { neutral-neutral collisions }\end{array}$ & $2.00 \times 10^{-14}\left(T_{\mathrm{gas}} / 300\right)^{0.5}$ & [15] \\
\hline 67 & $\mathrm{O}+\mathrm{O}\left({ }^{1} \mathrm{D}\right) \rightarrow 2 \mathrm{O}$ & $8.00 \times 10^{-18}$ & [49] \\
\hline 68 & $\mathrm{O}+\mathrm{O}\left({ }^{1} \mathrm{~S}\right) \rightarrow 2 \mathrm{O}$ & $3.33 \times 10^{-17} \exp \left(-300 / T_{\text {gas }}\right)$ & {$[47]$} \\
\hline 69 & $\mathrm{O}+\mathrm{O}\left({ }^{1} \mathrm{~S}\right) \rightarrow \mathrm{O}+\mathrm{O}\left({ }^{1} \mathrm{D}\right)$ & $5.00 \times 10^{-17} \exp \left(-301 / T_{\mathrm{gas}}\right)$ & {$[47]$} \\
\hline 70 & $\mathrm{O}+\mathrm{O}_{2}(\mathrm{a}) \rightarrow \mathrm{O}+\mathrm{O}_{2}$ & $7.00 \times 10^{-22}$ & {$[46]$} \\
\hline 71 & $\mathrm{O}+\mathrm{O}_{2}(\mathrm{~b}) \rightarrow \mathrm{O}+\mathrm{O}_{2}$ & $8.00 \times 10^{-21}\left(T_{\text {gas }} / 300\right)^{0.5}$ & {$[47]$} \\
\hline 72 & $\mathrm{O}+\mathrm{O}_{2}(\mathrm{~b}) \rightarrow \mathrm{O}+\mathrm{O}_{2}(\mathrm{a})$ & $7.20 \times 10^{-20}\left(T_{\text {gas }} / 300\right)^{0.5}$ & {$[47]$} \\
\hline 73 & $\mathrm{O}\left({ }^{1} \mathrm{~S}\right)+\mathrm{O}_{2}(\mathrm{a}) \rightarrow \mathrm{O}+\mathrm{O}_{2}$ & $1.10 \times 10^{-16}$ & {$[48]$} \\
\hline 74 & $\mathrm{O}\left({ }^{1} \mathrm{~S}\right)+\mathrm{O}_{2}(\mathrm{a}) \rightarrow 3 \mathrm{O}$ & $3.30 \times 10^{-17}$ & [48] \\
\hline 75 & $\mathrm{O}\left({ }^{1} \mathrm{~S}\right)+\mathrm{O}_{2}(\mathrm{a}) \rightarrow \mathrm{O}\left({ }^{1} \mathrm{D}\right)+\mathrm{O}_{2}(\mathrm{~b})$ & $2.90 \times 10^{-17}$ & [48] \\
\hline 76 & $\mathrm{O}_{2}+\mathrm{O}\left({ }^{1} \mathrm{D}\right) \rightarrow \mathrm{O}_{2}+\mathrm{O}$ & $4.80 \times 10^{-18} \exp \left(67 / T_{\text {gas }}\right)$ & {$[48]$} \\
\hline 77 & $\mathrm{O}_{2}+\mathrm{O}\left({ }^{1} \mathrm{D}\right) \rightarrow \mathrm{O}_{2}(\mathrm{a})+\mathrm{O}$ & $1.60 \times 10^{-18} \exp \left(67 / T_{\text {gas }}\right)$ & [49] \\
\hline 78 & $\mathrm{O}_{2}+\mathrm{O}\left({ }^{1} \mathrm{D}\right) \rightarrow \mathrm{O}+\mathrm{O}_{2}(\mathrm{~b})$ & $2.56 \times 10^{-17} \exp \left(67 / T_{\mathrm{gas}}\right)$ & [51] \\
\hline 79 & $\mathrm{O}_{2}+\mathrm{O}\left({ }^{1} \mathrm{~S}\right) \rightarrow \mathrm{O}_{2}+\mathrm{O}$ & $4.30 \times 10^{-18} \exp \left(-850 / T_{\text {gas }}\right)$ & {$[47]$} \\
\hline 80 & $\mathrm{O}_{2}+\mathrm{O}\left({ }^{1} \mathrm{~S}\right) \rightarrow \mathrm{O}_{2}+\mathrm{O}\left({ }^{1} \mathrm{D}\right)$ & $3.20 \times 10^{-18} \exp \left(-850 / T_{\mathrm{gas}}\right)$ & [47] \\
\hline 81 & $\mathrm{O}_{2}+\mathrm{O}_{2}(\mathrm{a}) \rightarrow \mathrm{O}_{3}+\mathrm{O}$ & $2.96 \times 10^{-27}\left(T_{\text {gas }} / 300\right)^{0.5}$ & [48] \\
\hline 82 & $\mathrm{O}_{2}+\mathrm{O}_{2}(\mathrm{a}) \rightarrow 2 \mathrm{O}_{2}$ & $2.20 \times 10^{-24}\left(T_{\text {gas }} / 300\right)^{0.5}$ & [43] \\
\hline 83 & $\mathrm{O}_{2}+\mathrm{O}_{2}(\mathrm{~b}) \rightarrow 2 \mathrm{O}_{2}$ & $4.00 \times 10^{-24}\left(T_{\mathrm{gas}} / 300\right)^{0.5}$ & [47] \\
\hline 84 & $\mathrm{O}_{2}+\mathrm{O}_{2}(\mathrm{~b}) \rightarrow \mathrm{O}_{2}(\mathrm{a})+\mathrm{O}_{2}(\mathrm{a})$ & $2.40 \times 10^{-24}\left(T_{\mathrm{gas}} / 300\right)^{3.8} \exp \left(-3080 / T_{\mathrm{gas}}\right)$ & {$[15]$} \\
\hline 85 & $\mathrm{O}_{2}+\mathrm{O}_{2}(\mathrm{~b}) \rightarrow \mathrm{O}_{2}(\mathrm{a})+\mathrm{O}_{2}$ & $3.60 \times 10^{-23}\left(T_{\text {gas }} / 300\right)^{0.5}$ & [47] \\
\hline 86 & $\mathrm{O}_{2}(\mathrm{a})+\mathrm{O}_{2}(\mathrm{a}) \rightarrow \mathrm{O}_{2}(\mathrm{~b})+\mathrm{O}_{2}$ & $9.00 \times 10^{-23} \exp \left(-560 / T_{\mathrm{gas}}\right)$ & {$[45]$} \\
\hline 87 & $\mathrm{O}_{2}(\mathrm{~b})+\mathrm{O}_{2}(\mathrm{~b}) \rightarrow \mathrm{O}_{2}(\mathrm{a})+\mathrm{O}_{2}$ & $3.60 \times 10^{-23}\left(T_{\mathrm{gas}} / 300\right)^{0.5}$ & {$[45]$} \\
\hline 88 & $\mathrm{O}_{3}+\mathrm{O} \rightarrow 2 \mathrm{O}_{2}$ & $8.00 \times 10^{-18} \exp \left(-2060 / T_{\text {gas }}\right)$ & [47] \\
\hline 89 & $\mathrm{O}_{3}+\mathrm{O} \rightarrow 2 \mathrm{O}+\mathrm{O}_{2}$ & $2.90 \times 10^{-16} \exp \left(-11400 / T_{\mathrm{gas}}\right)$ & [15] \\
\hline 90 & $\mathrm{O}_{3}+\mathrm{O} \rightarrow \mathrm{O}_{2}+\mathrm{O}_{2}(\mathrm{a})$ & $1.00 \times 10^{-17} \exp \left(-2853 / T_{\mathrm{gas}}\right)$ & {$[15]$} \\
\hline 91 & $\mathrm{O}_{3}+\mathrm{O} \rightarrow \mathrm{O}_{2}+\mathrm{O}_{2}(\mathrm{~b})$ & $2.80 \times 10^{-21} \exp \left(-2300 / T_{\text {gas }}\right)$ & {$[15]$} \\
\hline 92 & $\mathrm{O}_{3}+\mathrm{O}\left({ }^{1} \mathrm{D}\right) \rightarrow \mathrm{O}+\mathrm{O}_{3}$ & $2.40 \times 10^{-16}$ & {$[15]$} \\
\hline 93 & $\mathrm{O}_{3}+\mathrm{O}\left({ }^{1} \mathrm{D}\right) \rightarrow 2 \mathrm{O}+\mathrm{O}_{2}$ & $1.20 \times 10^{-16}$ & {$[47]$} \\
\hline 94 & $\mathrm{O}_{3}+\mathrm{O}\left({ }^{1} \mathrm{D}\right) \rightarrow 2 \mathrm{O}_{2}$ & $1.20 \times 10^{-16}$ & [47] \\
\hline 95 & $\mathrm{O}_{3}+\mathrm{O}\left({ }^{1} \mathrm{D}\right) \rightarrow \mathrm{O}_{2}+\mathrm{O}_{2}(\mathrm{a})$ & $2.71 \times 10^{-16}$ & {$[15]$} \\
\hline 96 & $\mathrm{O}_{3}+\mathrm{O}\left({ }^{1} \mathrm{~S}\right) \rightarrow 2 \mathrm{O}_{2}$ & $4.63 \times 10^{-16}$ & [48] \\
\hline 97 & $\mathrm{O}_{3}+\mathrm{O}_{2} \rightarrow 2 \mathrm{O}_{2}+\mathrm{O}$ & $7.26 \times 10^{-16} \exp \left(-11400 / T_{\mathrm{gas}}\right)$ & {$[46]$} \\
\hline 98 & $\mathrm{O}_{3}+\mathrm{O}_{2}(\mathrm{a}) \rightarrow \mathrm{O}+2 \mathrm{O}_{2}$ & $5.20 \times 10^{-17} \exp \left(-2840 / T_{\text {gas }}\right)$ & [48] \\
\hline 99 & $\mathrm{O}_{3}+\mathrm{O}_{2}(\mathrm{a}) \rightarrow \mathrm{O}\left({ }^{1} \mathrm{D}\right)+2 \mathrm{O}_{2}$ & $1.00 \times 10^{-17}$ & {$[15]$} \\
\hline 100 & $\mathrm{O}_{3}+\mathrm{O}_{2}(\mathrm{a}) \rightarrow \mathrm{O}_{2}+\mathrm{O}_{3}$ & $3.00 \times 10^{-21}$ & [49] \\
\hline 101 & $\mathrm{O}_{3}+\mathrm{O}_{2}(\mathrm{~b}) \rightarrow 2 \mathrm{O}_{2}+\mathrm{O}$ & $7.33 \times 10^{-18}\left(T_{\text {gas }} / 300\right)^{0.5}$ & [48] \\
\hline 102 & $\mathrm{O}_{3}+\mathrm{O}_{2}(\mathrm{~b}) \rightarrow \mathrm{O}_{3}+\mathrm{O}_{2}$ & $7.33 \times 10^{-18}\left(T_{\text {gas }} / 300\right)^{0.5}$ & [48] \\
\hline 103 & $\mathrm{O}_{3}+\mathrm{O}_{2}(\mathrm{~b}) \rightarrow \mathrm{O}_{3}+\mathrm{O}_{2}(\mathrm{a})$ & $7.33 \times 10^{-18}\left(T_{\text {gas }} / 300\right)^{0.5}$ & [48] \\
\hline 104 & $\begin{array}{l}\mathrm{O}_{3}+\mathrm{O}_{3} \rightarrow \mathrm{O}+\mathrm{O}_{2}+\mathrm{O}_{3} \\
\text { wall recombination / quenching }\end{array}$ & $1.65 \times 10^{-15} \exp \left(-11433 / T_{\mathrm{gas}}\right)$ & [15] \\
\hline 105 & $\mathrm{O} \rightarrow 1 / 2 \cdot \mathrm{O}_{2}$ & $\gamma_{\mathrm{O}}=0.1438 \cdot \exp (2.5069 / p[\mathrm{~m}$ Torr $])$ & {$[43],[15]$} \\
\hline 106 & $\mathrm{O}\left({ }^{1} \mathrm{D}\right) / \mathrm{O}\left({ }^{1} \mathrm{~S}\right) \rightarrow 1 / 2 \cdot \mathrm{O}_{2}+\mathrm{O}$ & $\gamma_{\mathrm{OD}}=\gamma_{\mathrm{OS}}=1=0.5($ rec $)+0.5($ quen $)$ & {$[45],[44]$} \\
\hline 107 & $\mathrm{O}_{2}(\mathrm{~b}) \rightarrow \mathrm{O}_{2}$ & $\gamma_{\mathrm{O} 2(\mathrm{~b})}=0.007 / 0.1$ & {$[43] /[44]$} \\
\hline 108 & $\mathrm{O}_{3} \rightarrow$ products & $\gamma_{\mathrm{O} 3}=0.001$ & assumed \\
\hline
\end{tabular}

Table 1. $\mathrm{O}=\mathrm{O}\left({ }^{3} \mathrm{P}\right), \mathrm{O}_{2}=\mathrm{O}_{2}\left(\mathrm{X}^{3} \Sigma_{\mathrm{g}}^{-}\right), \mathrm{O}_{2}(\mathrm{a})=\mathrm{O}_{2}\left(\mathrm{a}^{1} \Delta_{\mathrm{g}}\right), \mathrm{O}_{2}(\mathrm{~b})=\mathrm{O}_{2}\left(\mathrm{~b}^{1} \Sigma_{\mathrm{g}}^{+}\right), T_{\mathrm{e}}$ in eV, $T_{\text {gas }}, T_{\text {ion }}=2 T_{\text {gas }}$ in $\mathrm{K}$. 